\title{
Lutero desde América Latina
}

\author{
Alicia Mayer \\ Universidad Nacional Autónoma de México \\ Instituto de Investigaciones Históricas \\ amayer@unam.mx
}

Recepción: 14/04/2019, Aceptación: 27/07/2019, Publicación: 04/12/2019

\begin{abstract}
Resumen
Este trabajo se propone analizar la percepción que de Martín Lutero se ha tenido en América Latina a lo largo de su historia. Este contexto no ha sido un campo en el que se ha profundizado lo suficiente y, de hecho, podría percibirse el tema sobre el reformador y su propuesta teológica como algo totalmente ajeno al ámbito Latinoamericano. Sin embargo, resulta de sumo interés la manera en que ha sido abordado, estudiado, atacado o comprendido el otrora fraile agustino alemán en un mundo que fue heredero de los valores hispánicos y contrarreformistas desde los tiempos mismos de su conformación, primero, como colonias y después por estados nacionales con una herencia histórica y un bagaje cultural que condiciona la forma en que el personaje histórico ha sido visto a lo largo del tiempo.
\end{abstract}

Palabras clave

Martín Lutero; América Latina; herejía; Iglesia católica; Contrarreforma; protestantismo; catolicismo

\section{Abstract \\ Luther from Latin America}

This paper aims to analyze the perception of Martin Luther in Latin America throughout its history. This context has not been sufficiently studied in depth and, in fact, the topic of the reformer and his theological proposal could be perceived as something totally foreign to the Latin American sphere. However, of great interest is the way in which the former German Augustinian monk has been approached, studied, attacked or understood in a world that was heir to Hispanic and counter-reformist values since the very times of its formation, first, as colonies and then as nation states with a historical heritage and a cultural background that shape how this historical character has been seen over time.

\section{Keywords}

Martin Luther; Latin America; heresy; Roman Catholic Church; Counter-Reformation; Protestantism; Catholicism 


\section{Lutero desde la perspectiva de América Latina}

En 1517, cuando el fraile alemán Martín Lutero presentó sus 95 tesis sobre las Indulgencias en Wittenberg, apenas se abría un horizonte de evangelización en las inmensas tierras - aún en su mayor parte desconocidas para la conciencia europea- que habían recibido el nombre de "América». Una década antes, en 1507, otro alemán, Martín Waldesemüller, había pensado en el navegante florentino Américo Vespucio para bautizar aquella "cuarta parte del mundo» con su nombre. Lutero supo de la expansión del catolicismo a esas regiones ${ }^{1}$ y también el cisma luterano fue noticia al otro lado del Atlántico. Una carta de Hernán Cortés expresaba el interés del conquistador de México por conocer los hechos en Alemania:

Holgado he de saber el buen ardid que las galeras hicieron en tomar aquel lugar de moros y también vi las nuevas que decís del recibimiento que se hizo en Ávila, y no son desa calidad las nuevas que yo quería que me escribiésedes, sino que en cuantas cartas me enviásedes vinieran muy largas las nuevas que hubiera dentro de la casa de la emperatriz y mudanzas de gente de corte y cosas del reino y nuevas de Portogal y de la frontera y cosas de Francia y de Inglaterra y del Lutero y Concilio y de venida de Su Majestad y cosas del turco y del papa y de las señorías y de Italia y del rey de Hungría y cosas de la casa del emperador y oficiales que en ella se mudaren y provisiones y encomiendas y dignidades que proveyeren y siempre que desta calidad las haya, me lo haced saber muy por extenso».2

Desde entonces, se perfilará en la historiografía hispánica una interesante panorámica sobre la recepción de la figura y el pensamiento de Martín Lutero en el ámbito ibérico e hispanoamericano. Este ensayo pretende hacer un sucinto seguimiento de esa interpretación a partir de algunos testimonios desde el siglo XVI hasta nuestros días. Con ello deseo sumarme a la discusión académica de cara a la quingentésima conmemoración de la Reforma.

En 2017, salió a la luz un trabajo en inglés de mi autoría sobre Lutero en América Latina que publicó la Oxford University Press en una magna obra de homenaje al reformador alemán. ${ }^{3}$ Para la presente colaboración, utilicé y amplié esa versión para ponerla ahora al alcance de un público de habla española. No se trata del mismo análisis solamente traducido, ya que este último se ha enriquecido con nuevos hallazgos documentales y ha visto ampliadas las conclusiones, aunque sigue las propuestas metodológicas del ensayo original. Al decir de Hans Jürgen Prien, «el historiador no puede desistir de combinar la descripción crítica,

1. Marcel Bataillon (1950).

2. Hernán Cortés en José Luis Martínez (ed.) (1991: 312). Agradezco a la Dra. Carmen Martínez el haberme proporcionado esta referencia.

3. Alicia Mayer (2017). 
históricamente correcta, con la interpretación teológica». ${ }^{4} \mathrm{Si}$ bien esto es real y aunque se buscará un equilibrio en lo que marca esa tendencia, lo cierto es que la formación histórica de quien esto escribe inclina más la balanza al análisis que destaca el estudio y la comprensión del pasado. No es la intención aquí hacer un examen de la discusión teológica que se ha dado sobre la doctrina de Lutero; tampoco lo es abordar la historia, el papel y la misión de la iglesia luterana en América Latina. Las limitaciones que impone un escrito breve para una publicación de esta naturaleza obligan necesariamente a dejar de lado otras cuestiones, tales como el desarrollo del luteranismo en particular y del protestantismo en general en los países latinoamericanos, lo que de hecho se ha venido haciendo con excelentes resultados. ${ }^{5} \mathrm{El}$ objetivo es, pues, descubrir la percepción, la interpretación, la idea que en el mundo iberoamericano ha existido sobre Lutero y su propuesta doctrinal, sin pretender tener una versión acabada o definitiva. En este ámbito hay un proceso interesante a lo largo de los siglos que refleja cómo ha cambiado la conciencia sobre este personaje en el tiempo. De ser considerado «emisario del demonio», Lutero pasó a ser un "genio religioso cuya vida y escritos cambiaron la marcha del cristianismo y de la iglesia». ${ }^{6}$ Aún en la historiografía actual, se ha celebrado por unos como el gran liberador del verdadero evangelio y por otros se ha interpretado como el destructor de la unidad de la Iglesia.? Mirar a esta figura histórica desde América Latina no es un asunto menor. Este ámbito de estudio ofrece la posibilidad de descubrir nuevos horizontes hermenéuticos. Las naciones que hoy conforman Iberoamérica comparten muchos rasgos culturales comunes, sin embargo, constituyen un espacio de gran diversidad geográfica, social, étnica, demográfica, lingüística y de enorme pluralidad de enfoques. El historiador puede analizar a Lutero en el pensamiento de teólogos, tanto protestantes como católicos, de intelectuales, científicos sociales, filósofos o sociólogos, que son al fin y al cabo distintas formas de apreciar al reformador desde diferentes ángulos. Este trabajo plantea coadyuvar a una perspectiva de estudio sobre Martín Lutero en un espacio de interpretación que no ha sido el tradicional europeo. Al tenerla, se pretende aportar elementos para el conocimiento del pensamiento cristiano en el continente americano.

A mediados del siglo xx, el historiador Juan A. Ortega y Medina advirtió sobre la importancia de analizar a Lutero y su doctrina desde la perspectiva de Hispanoamérica, pues prácticamente no existían autores en este contexto que lo

\section{Hans-Jürgen Prien (1998: 91).}

5. Saranyana, Josep Ignasi (dir) y Carmen Alejos Grau (coord) (2002); Hans-Jürgen Prien (1985). Como ejemplo, cabe mencionar los importantes trabajos de Walter Altmann y Westhelle citados en la bibliografía general de este trabajo.

6. Sabino Sola (1973); Gregorio Pérez G., en Juan Stumme, et. al. (1983: 73). Alicia Mayer (2008).

7. Juan Stumme (1983: 15-16). 
tratasen de manera expresa. ${ }^{8}$ Asimismo, en el prólogo a su libro Lutero en España y América española, el historiador jesuita Ricardo V. Feliu señaló que su obra, «más que al público español, [iba] destinada a los lectores de Hispanoamérica, por donde las diferentes confesiones religiosas penetran y se extienden».. Para finales de los ańos setenta del siglo pasado, el panorama se había ampliado. El gran luterólogo español Ricardo García Villoslada advertía sobre un viraje en sentido positivo, afirmando que la figura de Martin Lutero había cobrado gran actualidad entre los estudiosos de habla española. El agudo juicio condenatorio del investigador católico sobre Lutero estaba cediendo lugar a una mirada más objetiva, y dentro del catolicismo era juzgada su persona con una benignidad desconocida antes del siglo Xx. ${ }^{10}$ Esto se debe, desde luego, a un cambio gradual de paradigmas reflejado en la paulatina pérdida de relevancia en el mundo moderno secularizado de la religiosidad en general y del dominio ideológico de la Iglesia en particular, donde Lutero pudo ser visto como símbolo con valores laicos y seculares.

Cabe hacer notar, para terminar con esta presentación introductoria, que América Latina es la región que cuenta con el mayor número de católicos e hispanohablantes en el mundo, lo cual le da a este espacio una importancia enorme en cuanto a lectores, especialistas y estudiosos se refiere. Por su parte, el teólogo alemán Helmar Junghans, señalaba que, en 1983, para conmemorar el nacimiento de Lutero, se había discutido mucho en el espacio latinoamericano sobre el reformador y su ideología en jornadas interconfesionales, interdisciplinarias e internacionales, lo que «jamás había acontecido antes». ${ }^{11}$ Fueron también múltiples los foros en 2017 para recordar los 500 años de las 95 tesis, hecho que se considera el inicio de la Reforma. Hoy sigue vigente la necesidad de atender el significado de Lutero en nuestro contexto para el diálogo interreligioso e intercultural, sobre todo, delante de los problemas sociales que, para algunos, encuentran respuestas en Lutero. El fenómeno de la globalización ha llevado al análisis de la doctrina luterana desde diferentes perspectivas. En la actualidad hay una gran aportación de autores laicos, de distinta formación, o bien de individuos pertenecientes a comunidades eclesiásticas diversas. Se ha visto que hay problemas sociales, económicos, políticos y teológicos imbricados en el protestantismo que tienen un impacto directo en la historia latinoamericana. El fenómeno latinoamericano es muy complejo: no existe hoy una sola iglesia institucional en América Latina, sino una enorme pluralidad confesional, diversas denominaciones cristianas, iglesias pentecostales, carismáticas, así como también cultos hispano-mestizos, indígenas,

8. Juan A. Ortega y Medina, Reforma y modernidad en Cristina González Ortiz y Alicia Mayer (editoras) (2013: I, 39) y «Lutero y su contribución a la modernidad», en Cristina González y Alicia Mayer (editoras) (2013: I, 437-456).

9. Ricardo Viejo Feliu (1956).

10. Ricardo García Villoslada (1973: 3).

11. Helmar Junghans (2001: 121). 
afroamericanos y asiáticos que representa un verdadero desafío para el estudioso. ${ }^{12}$ La interpretación de Lutero que hemos encontrado en este ámbito presenta muchas formas y es vivida en muchos espacios de manera distinta. ${ }^{13}$ Por ésta y otras circunstancias, existen de sobra razones para meterse de lleno en el estudio de Lutero desde América Latina.

\section{Lutero en perspectiva histórica}

Se puede decir, sin lugar a dudas, que Lutero nunca fue ajeno a la historiografía latinoamericana. Está muy presente desde el siglo xvi en el discurso de cronistas, teólogos, misioneros y escritores en los territorios coloniales, sobre todo en los dos grandes virreinatos de México y Perú, pero también en Colombia, Chile, Venezuela y el virreinato rioplatense. Como apunté líneas atrás, la presente contribución tiene como objetivo dar una perspectiva histórica de la imagen que se ha tenido de Lutero en Iberoamérica durante 500 años. El catálogo de referencias sobre Lutero en cinco siglos resulta, sin duda, muy copioso. No puede pretenderse, por tanto, en un artículo panorámico, agotar la materia. ${ }^{14}$

Durante más de cuatro siglos, la imagen de Lutero se construyó a partir de las pautas de un discurso retórico fijo. ${ }^{15} \mathrm{Al}$ decir del teólogo Harding Meyer, fue transmitida una grotesca caricatura del reformador, una representación desfigurada de su persona. ${ }^{16}$ Para la época colonial, tomo algunos ejemplos. Ya que previamente mencionamos a Hernán Cortés, podemos recordar la conocida coincidencia, por supuesto inventada, que hace el franciscano Geronimo de Mendieta, tomada a su vez del cronista Lasso Lobo de la Vega, del año de nacimiento del conquistador español y el reformador alemán, bajo el presupuesto de una compensación providencial de pérdida y recuperación de almas para la Iglesia católica.

No carece de misterio que el mismo año que Lutero nació en Islebio [Eisleben] villa de Sajonia, naciese Fernando Cortés en Medellín, Villa de Espańa en Extremadura; aquel maldito hereje para turbar el mundo y meter bajo la bandera del demonio a muchos de los fieles que de padres y abuelos y muchos tiempos atrás eran católicos, y este cristiano capitán para atraer al gremio de la iglesia católica romana infinita multitud de gentes que por años sin cuento habían estado debajo del poder de Satanás envueltos en vicios y ciegos con la maldad de la idolatría [...] y así también

12. Todavía queda por hacerse la investigación del papel de Lutero en las Iglesias carismáticas que han proliferado en América Latina sobre todo a partir de la década de 1980.

13. Hans-Jürgen Prien (1998: 90).

14. En 2008, salió a la luz mi libro Lutero en el paraíso, un amplio análisis de la imagen de Lutero en el México virreinal y de principios del siglo xIx. Recomiendo su consulta para ampliar la visión sobre el reformador alemán en la parte que se refiere al mundo colonial en este trabajo.

15. Mayer (2008).

16. Harding Meyer (1961: I, 13). 
en un mismo tiempo, que fue el año de [15]19, comenzó Lutero a corromper el Evangelio entre los que lo conocían[...] y Cortés a publicar (el Evangelio) fiel y sinceramente a estas gentes que nunca de él habían tenido noticia». ${ }^{17}$

Pero no sólo en México, sino también, como señala el historiador, José de la Riva Agüero, «hasta el corazón del remoto y catolicísimo virreinato peruano llegaban de continuo los ecos del gran movimiento de la Reforma». ${ }^{18}$ El connotado escritor cuzqueño conocido en las letras universales como el Inca Garcilaso (1539-1616) definió a Lutero como «aquel grosísimo y fiero sajón». ${ }^{19} \mathrm{La}$ Inquisición se estableció oficialmente en Lima en 1570 y «fue especialmente sangrienta con los sospechosos de seguir a Lutero» ${ }^{20}$ Asimismo el círculo humanista entorno a la llamada Academia Antártica peruana atacaba sistemáticamente al ex fraile para no dejar duda sobre su filiación ideológica contrarreformista. ${ }^{21}$ Así, muchas obras se produjeron para anatematizar al malvado hereje.

En la Nueva Granada (hoy Colombia) el clérigo y cronista de la Nueva Granada Juan de Castellanos (1522-1607) lo incluía en un canto poético haciendo alusión a él como «bestia falsa y desalmada», "gran charlatán y monstruo fiero». ${ }^{22}$ Por su parte, Gonzalo Jiménez de Quezada (1509-1579), conquistador y fundador de Santa Fe de Bogotá, cuyo carácter de aguerrido soldado no obstó para que también fuera cronista y hombre de letras, se hallaba bien enterado del entramado político europeo. En su Antijovio, daba noticia del encuentro del monje sajón con el emperador Carlos V en Worms en el año de 1521 y aseguraba que aquel fraile era una pestilencia y sus causas frívolas. ${ }^{23}$

La reforma evangélica en el mundo germánico fue un hecho contemporáneo a la conquista y la colonización americana por parte de España, la nación que, al mismo tiempo que avanzaba por el Nuevo Mundo, se proclamaba la campeona en la defensa de la fe católica y, junto con el papado, lucharía denodadamente contra el protestantismo. Para los hispanos, Lutero sería el archienemigo de la fe, el hereje incorregible y su figura sería desde entonces sistemáticamente anatematizada y atacada. El otrora monje agustino sería señalado como sinónimo de maldad, de miseria, de transgresión, de desobediencia, de inmoralidad y el responsable del desorden e inestabilidad de Europa. Así lo volvemos a ver, por ejemplo, reflejado en el poema La Christiada (1611), de fray Diego de Hojeda, regente de los estudios de predicadores de Lima, obra dedicada al virrey de Perú, que recibió elogios de Lópe de Vega:

17. Mendieta (1971: Libro III, cap. I, p. 175). Ver también Mayer (2016: 179-203).

18. José de la Riva Agüero (1962: 134).

19. Inca Garcilaso (2016: 127).

20. Felipe Barreda Laos (1964: 102 y 22).

21. Rosa García Gutiérrez (1998: 321).

22. Juan de Castellanos (2004: canto segundo, p. 325).

23. Carlos Valderrama Andrade (1965: 234). 


\author{
Al que fundó la seta luterana \\ Monstruo del mundo, parto del infierno, \\ Que no creyó la libertad umana, \\ Viendola el mismo su infeliz govierno: \\ Azote de la diestra soberana, \\ Después echado al fuego del infierno, \\ O si tu odiosa madre no naciera \\ O ya que mal nació, no te pariera $[\mathrm{sic}]^{24}$
}

Por su parte, las regiones que andando el tiempo constituirían las naciones Iberoamericanas fueron herederas culturales de la monarquía universal católica (Espańa y Portugal) y de la Contrarreforma, el movimiento de depuración interna llevado a cabo en el siglo xvi por la Iglesia de Roma, profundamente contraria a la propuesta reformadora alemana. La postura religiosa política que emanó del Concilio de Trento (1545-1563) tuvo hegemonía en América Latina ${ }^{25}$ por espacio de casi cuatro siglos. La manera en que se ha interpretado a Lutero en estas regiones ha obedecido a cuestiones de ideología y de circunstancias históricas. Así, se formuló una opinión ajena al personaje histórico, como modelo o arquetipo de elementos contrarios a los del catolicismo romano y de valores culturales opuestos a los que defendían la monarquía universal hispana y la Iglesia romana. Lutero fue abordado desde un punto de vista polémico, que evitó el análisis de contenido doctrinal. Se le despersonalizó siguiendo una estrategia psicológica muy eficaz para neutralizar su posible influencia, para deshabilitarlo o reducir su capacidad de «daño». La imagen negativa e infamante se replica todavía en el siglo XIX, durante la época de las independencias y de la conformación de las naciones americanas por una interminable cadena causal que se remonta hasta el siglo Xvi. Incluso, en México, los próceres de la Independencia, sobre todo Hidalgo y Morelos fueron tildados de luteranos y enjuiciados por la Inquisición. ${ }^{26}$

En la centuria decimonónica se interpretó a Lutero desde la perspectiva de las nacientes repúblicas que buscaban definir su identidad ${ }^{27}$ propia. Por otra parte, se seńalaba lo pernicioso que habían resultado para Alemania sus «paradojas», «sectarismos» y "contradicciones». Esas jóvenes naciones, por herencia histórica, rechazaban formalmente la herejía, pero también es verdad que había escasa claridad sobre los fundamentos teológicos del protestantismo en general

24. Diego de Hojeda (1611: libro 7, 189-190).

25. El concepto de "América Latina» se empleó, particularmente en la historiografía francesa, en la segunda mitad del siglo XIx para designar a las regiones americanas donde se hablaban lenguas derivadas del latín. También hacía referencia a la zona que era distinta de la América, protestante y sajona. Ver Jean-Pierre Bastian (1994: 11). En este trabajo, se empleará el término de «América Latina», "Latinoamérica» e "Iberoamérica» y se incluirá aquí el ámbito de Brasil y del Caribe.

26. Mayer (2008: 352-371).

27. Para cuestiones de identidad véase Carlos Mondragón (1994); Alicia Mayer (2008); Rudolfo Blank (2008: 6-21) y Carmen Rodríguez y José D. Rodríguez (2010). 
y del luteranismo en particular. En 1811, en plena guerra de Independencia en México, la Inquisición consignó a un hombre que opinaba que «Lutero, sin embargo de ser hereje, tenía algunas opiniones buenas». ${ }^{28}$ Algunos años después, un cercano colaborador de Simón Bolívar, Manuel Lorenzo Vidaurre (1773-1841) señalaba que Lutero no merecía el nombre de hereje tan sólo por disentir de la Iglesia católica y que no debía habérsele perseguido por motivos de conciencia. ${ }^{29}$

Para Enrique Dussel, los fenómenos protestantes tuvieron su oportunidad en América Latina en la segunda mitad del siglo xIx, ligado a los movimientos liberales, más inclinados a la tolerancia, así como a las sociedades masónicas, con un impacto en las instituciones pedagógicas. ${ }^{30}$ Casi por lo general, el historiador encuentra a Lutero en las fuentes de esta época como un tema tangencial, pero presente y constante, que se repite sin cesar no sólo en las obras de autores importantes, sino también en la voz de la opinión pública a través de la prensa.

Según Jean Pierre Bastian, más que la teología de la reforma luterana y calvinista, fueron los temas anticlericales, tales como la negación del culto a los santos y el sacerdocio universal de los fieles, los que se pusieron sobre la mesa de discusión. ${ }^{31} \mathrm{Al}$ respecto, comenta Mario Miegge que «los liberales y los anticlericales del siglo XIX no estaban listos para entender la crisis religiosa de los hombres del siglo XVI, pero vieron en la rebelión de Lutero contra el Papa el primer rompimiento de las cadenas autoritarias de la Edad Media». ${ }^{32} \mathrm{El}$ ministro religioso, misionero por más de cuarenta años en Chile y fundador en ese país de la primera iglesia protestante, David Trumbull (1819-1889) señaló que Lutero había rechazado en su tiempo «el yugo ominoso y fatal del absolutismo sacerdotal» y era, por consiguiente, el restaurador de la libertad. ${ }^{33}$ Así, en esta época se atisban ya algunos enfoques favorables en la percepción del reformador, sobre todo en los medios intelectuales y seculares, aunque todavía no de manera contundente.

Para llegar a una visión positiva de Lutero ciertamente influyeron los movimientos liberales, pero también la entrada de grupos de inmigrantes y de misio-

28. «Denuncia de Doña María Dolores López contra un hombre llamado Miguel y otro Mariano Callejo por ser adictos a la guerra» (1811).

29. Manuel Lorenzo Vidaurre (1828: 124-125).

30. Enrique Dussel, «Historia del fenómeno religioso en América Latina», en Hans-Jürgen Prien (1998: 75).

31. Jean Pierre Bastian, «La implantación y el desarrollo del efecto de doctrina y efecto de organización en el protestantismo misional en América Latina», en Hans-Jürgen Prien (1998: 64). 32. Mario Miegge (2016). Ese parece haber sido el caso, por citar un ejemplo, de Melchor Ocampo (1814-1861), quien en 1851 ante el congreso del estado de Michoacán, dijo que se debía reconocer el natural derecho que tiene cada hombre para adorar a Dios según las instrucciones de su conciencia, una clara tesis luterana que salió al cuento al calor de la discusión en torno a la reforma del arancel de obvenciones parroquiales. Melchor Ocampo (1900: 2).

33. Cit. de La Piedra, Valparaíso. 25 jul. 1871, año II, n. 18:7. En Arcos (2013). Versión en línea: <http://dx.doi.org/10.1590/S0100-85872013000100006>. Consultado el 18 de noviembre de 2016. 
neros protestantes a los países católicos latinoamericanos, a raíz de la apertura de los mismos al comercio internacional y de la promulgación de la libertad de cultos a lo largo de esa centuria y de principios del siglo xx. Éstos reflejan un claro interés por destacar al personaje y su pensamiento en términos favorables. Además, esto coincidió con la tendencia general de la época que comenzó a matizar o atenuar el ánimo hostil centenario de la Contrarreforma, debida a la secularización, junto con el desarrollo de estudios y análisis científicos inclinados a ejercer una comprensión crítica mesurada y más objetiva de las visiones religiosas. Para el liberal mexicano José María Luis Mora (1794-1850), la reforma de Lutero significó el tránsito de las costumbres y constituciones antiguas a un orden del todo nuevo». ${ }^{34} \mathrm{~A}$ fines de la centuria, su compatriota el historiador Vicente Riva Palacio (1832-1896) analizaba la actuación de Lutero ante la Dieta de Worms y lo definía como uno «los grandes hombres» que habían cambiado la historia. ${ }^{35}$ El también liberal Ignacio Ramírez (1818-1879), defensor de la libertad de cultos en México, de la separación de la religión de la vida política, aseguraba que la Edad Media había comenzado con Constantino y había acabado con Lutero (haciéndolo precursor de la modernidad). Externó que «Lutero emancipó a Europa del poder de los papas, santificó la libertad del hombre en la libertad de conciencia».36 Por su parte, el pensador cubano José Martí (18531895) escribió en abril de 1884 que: «todo amante de la libertad debe colgar en su muro, como el de un redentor, el retrato de Martín Lutero", mientras que su compatriota Enrique José Varona afirmaba que la causa de la Reforma se personalizaba en aquel fraile. ${ }^{37}$ Esta característica fundacional de la reforma religiosa llevada bajo el liderazgo de ex monje alemán mereció también el aplauso del escritor uruguayo José Enrique Rodó (1871-1917) quien admiró «la fuerza vehemente y arrebatada de Lutero... el motor de las transformaciones morales». Su palabra apasionada «convirtió en dóciles sonámbulos a los hombres y a los pueblos». ${ }^{38}$ Por su parte, el escritor y poeta argentino, Esteban Echeverría (18051851) criticaba el aspecto intolerante del catolicismo y recordaba a Lutero «luchando cuerpo a cuerpo con el coloso decrépito del Vaticano y aniquilando su infalibilidad», ${ }^{39}$ mientras que el liberal y también argentino Juan Bautista Alberdi (1810-1884) defendía la tolerancia de cultos y extrañaba la falta que habían hecho en España impulsores del gobierno representativo como Lutero, Descartes y Bacon. ${ }^{40}$

34. José María Luis Mora (1837: 319-320).

35. Vicente Riva Palacio (1996: 248).

36. Ignacio Ramírez (1889: Microfilm 170-171). Universidad de Illinois.

37. Ariel Jordán Martínez (2011: 347); Martin Franzbach (1998: 347-352). Enrique J. Varona (2016: 59).

38. Rodó en Juan O. Pons (2017: s/p).

39. Esteban Echeverría (1991: 55).

40. Juan A. Alberdi (2005: 15, n. 9). 
Uno de los principales argumentos entre algunos intelectuales, políticos y escritores en el siglo xIx fue rescatar la valía de Lutero como precursor del alemán moderno. El barón Otto de Brackel-Welda, un periodista que llegó a México cuando el emperador Maximiliano promulgaba el decreto de tolerancia de cultos (1865), aseveró que «la grandiosa e importante figura del reformador Lutero» había cambiado el rumbo de los destinos intelectuales de Alemania a través de sus escritos, de la traducción de la Biblia y del canto popular. ${ }^{41}$ Otros, como el escritor mexicano Ignacio Manuel Altamirano (1834-1893) destacaba al ex fraile agustino como «el gran reformador de la educación en Alemania». ${ }^{42}$ Desde Argentina, Domingo Faustino Sarmiento (1811-1888) opinaba que la libre lectura de la Biblia había echado los cimientos de la educación popular que había cambiado la faz de las naciones que practicaban el protestantismo. Añadió que la gran contribución de Lutero había sido «el hábito del libre examen, el cultivo de la dignidad personal, la concientización de la práctica institucional democrática y la predisposición a la educación», elemento que en su parecer le confería a esta confesión una superioridad moral sobre el mundo católico. ${ }^{43}$ Sarmiento también señaló, como lo haría su compatriota Esteban Echeverría, que había sido la corrupción de la Iglesia la causa de la reacción de Lutero.. ${ }^{44}$ Igualmente en este tenor, el político conservador mexicano Lucas Alamán (1792-1853) pensaba que la «herejía de Lutero» había nacido con ocasión de la ominosa venta de indulgencias concedidas por el Papa, cuyas ganancias habían sido encauzadas a la construcción de la basílica de San Pedro en Roma, ayudando no poco a ello, como había señalado el padre jesuita Juan de Mariana (1536-1624), a «los abusos y vicios que se veían, donde y en quien menos fuera razón». ${ }^{45} \mathrm{Al}$ explicar las causas de la Reforma, además de lo anterior, Alamán aducía — sin hacer un juicio de la personalidad de Lutero ni condenarlo- que éste había trastornado con su doctrina a toda Alemania y había sido la

41. Otto de Brackel-Welda (1957: 92-109). Sobre la traducción de Lutero de la Biblia, véase Herón Pérez (2014).

42. Ignacio M. Altamirano, «El maestro de escuela», El Federalista, 20 de febrero de 1871, p. 1-3. Lutero contribuyó a crear un nuevo enfoque no sólo en materia de religión, sino también en educación. Para los pensadores latinoamericanos que buscaban esto mismo en sus sociedades, resultaba revelador. Sus propuestas en materia de educación incluían los siguientes argumentos: El estado debía regir las escuelas. Sostuvo ante los príncipes que se debía obligar a los padres a enviar a sus hijos a la escuela. Las instituciones de su tiempo eran inadecuadas porque hacían demasiado hincapié en la escolástica y exageraban el valor de la retórica. Abogaba por una disciplina rígida, pero humana. Proponía un plan de estudios para la educación primaria que consistiera en religión, latín, música e historia y en la universidad, la Biblia sería el eje del plan, se pondría énfasis en el latín, el griego y el hebreo en la retórica, la lógica y la poesía. Javier Aranda afirmaba que Lutero era «el mayor promotor de la lectura de todos los tiempos» y que su sugerencia de leer directamente la Biblia, había favorecido el pensamiento crítico. Ver 2011. Ver también Litvin Roldán Tomasz Suárez (2004) y Leopoldo Heiman (2005).

43. Domingo Faustino Sarmiento (2006: 131-135).

44. Esteban Echeverría (1991: 155).

45. Lucas Alamán (1849: T. III, 58). 
causa de que se separasen tantas naciones de la iglesia romana. No obstante que hay ejemplos de estas inclinaciones por rescatar lo positivo del legado de Lutero, aún imperaba en la centuria decimonónica el viejo y rancio estereotipo, aún en intelectuales de vasta cultura y conocimientos. Ejemplo de esto lo da el historiador mexicano Carlos María de Bustamante (1774-1848), rabioso detractor del ex fraile agustino y de la Reforma, quien afirmaba que Lutero seguramente se hallaba «sepultado en los infiernos»" ${ }^{46}$ siguiendo la línea directriz imperante desde el siglo xvi. Por su parte, el intelectual peruano José de la Riva Agüero aseguró que esa "calamitosa pseudorreforma» había frustrado la unidad de la cultura de Europa, pues el protestantismo germano de Lutero había negado el Renacimiento latino promovido por la Iglesia católica. ${ }^{47}$

Mucho se escribió también en el siglo XIX sobre el talante anímico, la personalidad, o bien el aspecto psicológico de Lutero. Se había señalado como intérprete subjetivo y equivocado de las sagradas escrituras, hombre angustiado y atormentado por sus propios conflictos internos, sujeto codicioso, licencioso, lascivo, desobediente, refractario, codicioso de los bienes de la Iglesia, inclinado a los excesos. Agustín Dueñas, el nombre de un cura con que al parecer firmaba el obispo de Michoacán, Clemente de Jesús Munguía, criticó la «pasión desenfrenada» del otrora fraile, mientras que Bustamante opinó que "durante su vida no cesó un punto de contradecirse, siempre anduvo en desacuerdo consigo mismo, en pugna con su propia doctrina». ${ }^{48}$ La corriente del Positivismo en México generó una obra de teatro sobre Lutero, la de Porfirio Parra, en la que describía la situación anímica del fraile agustino que lo llevaría a escribir las 95 tesis contra las indulgencias. Otras tendencias intelectuales permitieron que en Colombia pudiera ser escrita la novela "Luterito» de Tomás Carrasquilla (1858-1940) que no trata propiamente del reformador, sino que pinta el ambiente y los extremos ideológicos que se vivieron en ocasión a la guerra civil de 1876-1877 en el pueblo ficticio de San Juan de Piedragorda, donde el protagonista, el sacerdote Casafús, fue tildado de ser un «nuevo Lutero», ${ }^{49}$ analogando a los dos personajes por su perfil psicológico. Sería motivo de otro ensayo darle seguimiento a lo que historiadores, teólogos y diversos autores del siglo xx disertaron sobre el tema de la psicología de Lutero. Basta recordar cómo Carlos Fuentes decía que la figura de «Martín Lutero es la dura, plebeya, estreñida imagen pintada por Cranach». ${ }^{50}$ Más aún, en un año tan reciente como 2013, un periodista brasileño, João Batista Prado Ferraz Costa, afirmaba que "por sus propios problemas psicológicos, Lutero negó el libre arbitrio del hombre». ${ }^{51}$

46. Carlos María de Bustamante (Andrés Cavo) (1852: t. III, 44).

47. José Riva Agüero, (1942: 61-74).

48. Citado en M. Ocampo (1900: I, 34-35) y Carlos María de Bustamante (1837, II, 24).

49. Porfirio Parra (1906); Juan Esteban Londoño (2013).

50. Carlos Fuentes (2011: capítulo 10).

51. João Batista Prado Ferraz Costa (2013). 
Volviendo al siglo XIX, no pueden quedar sin mención las múltiples referencias de Lutero en la prensa, tanto en la protestante como en la católica, ${ }^{52}$ siendo esta última la que observa aún gran virulencia, dándole al reformador dramáticas adjetivaciones peyorativas y donde se utilizaba con harta frecuencia el refrán de «la Iglesia en manos de Lutero», para señalar que se entregaba al lobo el cuidado de los corderos. En la contienda entre liberales y conservadores, Lutero quedaba redimido en el lado liberal, por las razones anteriormente explicadas.

A fines del siglo XIX y toda la primera mitad del xx, los protestantes, que llegaban cada vez en mayor número, sobre todo a países como Brasil, Argentina, México y Chile, buscaron también hacer proselitismo y ganar espacios dentro de las sociedades latinoamericanas..$^{53}$ Éstos contribuyeron para abrir un espectro que permitió una nueva interpretación de la figura del reformador, misma que, sin embargo, seguía chocando con las posturas más conservadoras y trataba de ser frenado por la Iglesia católica. En este tiempo dominaban en el ambiente intelectual latinoamericano los juicios negativos que de Lutero habían hecho teólogos e historiadores españoles, como Jaime Balmes, Emilio Castelar o Donoso Cortés, en vez de hacerlo los análisis académicos que produjeron varios teólogos alemanes en esa misma época. ${ }^{54}$

\section{El siglo Xx: una nueva aproximación}

El siglo xx es un gran hito en la interpretación sobre la figura de Lutero, sobre todo después del Concilio Vaticano II (11 octubre 1962-diciembre de 1965). Empero, mucho antes de la reunión ecuménica, el reformador había ya merecido la atención de escritores, historiadores y poetas de la talla del nicaragüense Rubén Darío (1867-1916) y del mexicano Amado Nervo (1870-1919). Este último describía a Lutero, en tono benevolente, como «ese hombre de cara redonda y plácida, el enamorado de Catalina Bora, el formidable reformador». ${ }^{55}$

Mucho impulso dio al interés por Lutero el libro Martín Lutero. Emancipador de la conciencia del pastor evangélico Federico Fliedner, autor nacido en Alemania, pero "entrańablemente identificado con España e Iberoamérica». ${ }^{56}$

52. Rubén Ruíz Guerra (2001: 259).

53. El caso de Brasil es digno de mención. Este país disputa a Alemania, Sudáfrica y Nigeria la tercera plaza en el ranking de los países con más protestantes en el mundo, después de Estados Unidos y el Reino Unido. Existen allí alrededor de treinta millones de Evangélicos. Ver David Stoll (2010).

54. El libro de Jaime Balmes, El protestantismo comparado con el catolicismo en sus relaciones con la civilización europea (1844) fue una contestación a la Histoire générale de la civilization en Europe, publicada por François Guizot en 1828. Están también las réplicas de otros autores como Emilio Castelar en su Discurso sobre la libertad religiosa (1880) o de Donoso Cortés, autor de varias epístolas y libros, entre los que puede destacarse su Ensayo sobre el catolicismo, el liberalismo y el socialismo de 1851 .

55. Amado Nervo (1993).

56. Federico Fliedner (1956). 
La obra, publicada en español por vez primera en Madrid en 1878, luego en 1913 y posteriormente en México en 1949 y 1956 relata la vida del «insigne agustino" y persigue el objetivo de rectificar las confusiones que "los adversarios de Lutero» habían promovido para "difamar al reformador». Su esfuerzo resultó en una biografía cálida y accesible a todos los públicos, que presentó una imagen muy positiva — quizá, hasta se podría decir, hiperdimensionada - del ex fraile agustino, «el valiente guerrero de Dios».

Parecían soplar aires nuevos que empezaban a disipar los viejos estereotipos que calificaban a Lutero como demonio o como un hombre psicológicamente patológico (siguiendo la línea trazada por los historiadores católicos alemanes H. Denifle y H. Grisar), pero lo cierto es que aún había que esperar varios años más en el mundo latinoamericano para ver que esa imagen empezara a disiparse. Incluso, el llamado "renacimiento de Lutero» ${ }^{57}$ en la historiografía, que se refiere a la ingente producción historiográfica alemana surgida con motivo del cuarto centenario de la Reforma (1917), encabezada por la trascendente obra de Karl Hull, a la que le siguieron las de los críticos posteriores Hans Joachim Iwand, Ernst Wolf y Heinrich Boehmer, buscó nuevos métodos y criterios en la investigación. Ésta, lamentablemente, no tuvo fuerte y definitivo impacto en la órbita de habla española, como bien lo percibió Alfonso Reyes, quien hizo énfasis en el talante conflictivo del reformador. ${ }^{58}$ El agudo juicio condenatorio de los investigadores católicos de antaño sobre Lutero parece no diluirse del todo en las primeras décadas de la centuria. Tanto así, que llama la atención que todavía en 1937, apareciera un libro en Brasil con argumentos aberrantes y muy lejanos de la objetividad histórica, el del padre católico Júlio Maria, con el título O Diabo, Lutero e o Protestantismo, que mereció incluso una reedición en $1950^{59}$ y que tuvo amplia circulación.

Fue hasta la segunda mitad del siglo xx en que se percibe ya de manera más franca un cambio de percepción en torno a Lutero. Una de las razones para ello la inspiró la iniciativa de algunas casas editoriales latinoamericanas por traducir y publicar la obra del reformador. Otro factor que incidió favorablemente fue el empeño de historiadores y de teólogos más abiertos a la comprensión del personaje histórico, para quienes había que señalar la importancia de Lutero y su legado. Bien vale la pena dedicar el siguiente apartado al breve repaso historiográfico de la evolución del pensamiento sobre Lutero.

En 1944 fue publicada en México la obra de Pierre Mavy: San Agustín, Lutero Pascal y un año después apareció el célebre trabajo de Jacques Maritain, Tres reformadores. Lutero, Descartes y Rousseau, publicado por Buenos Aires y Santiago de Chile a través de la editorial Excelsa, que literalmente inundó las

57. Manfred K. Bahmann (1967: v. I, xxiii).

58. Alfonso Reyes (1980: 412-418).

59. En H. Meyer (1961: 20). 
librerías latinoamericanas. Estas ediciones generaron mucho interés y detonaron una gran cantidad de trabajos sobre el reformador. En 1950 se tradujo en Buenos Aires la obra de Roland H. Bainton, Here I stand que vio la luz con el título de Lutero (Ed. Sudamericana, 1950) y en 1954 salió en México la traducción de Leonard S. Ingram: Martín Lutero, el fraile que conmovió al mundo. Dos años más tarde, en 1956, el Fondo de Cultura Económica de México publicó la de Lucien Febvre, Martín Lutero, un destino (editada por primera vez en Francia en 1927).$^{60}$ En 1959 el libro de J. A O’Brien fue traducido al portugués y salió de las prensas con el título Martinho Lutero: O Sacerdote Que Fundou o Protestantismo. Dos años más tarde, Carlos Gerhard tradujo la obra de Guiseppe Alberigo, La Reforma Protestante: Lutero, Melanchton, Zwinglio y Calvino (México, Ed. Hispanoamericana, 1961). Un momento muy significativo para la historiografía latinoamericana fue el tener acceso en castellano a la obra de Joseph Lortz Die Reformation in Deutschland (2 vol. Herder, Freiburg, 1939-40; 4 ed de 1962 que apareció con el título de Historia de la Reforma (Madrid, Taurus, 1963).

Desde 1967, y a lo largo de la década de los setenta, la editorial Paidós publicó en Argentina una serie de las obras más importantes de Martín Lutero en cinco volúmenes, labor que continuó la editorial La Aurora, acompañada de excelentes estudios introductorios, ${ }^{61}$ para «proporcionar al lector de habla española la posibilidad de entrar en contacto directo con el significativo y a la vez discutido reformadon». También se orientaba «a las decisiones que han de adoptarse en el mundo contemporáneo", clara premonición de los vertiginosos cambios de mentalidad religiosa que se sucederían a partir de esa década y «proporcionar a los lectores de habla castellana un acceso a los escritos de Lutero que han tenido una decisiva influencia en la formación de una comunidad eclesiástica separada de la del Papa». ${ }^{62}$ En suma, se necesitaron las traducciones al castellano y al portugués para que se conociera directamente y de primera mano el pensamiento de Lutero en estos confines, lo que repercutió en un mayor interés por parte de los especialistas, inmersos en un contexto lingüístico distinto al alemán, al inglés o al francés. Una edición completa en castellano de la obra de Lutero no existe, pero se ha avanzado considerablemente para traducir muchas de ellas y ponerlas al alcance del público latinoamericano. La propuesta luterana contenida en la monumental edición de Weimar generalmente se aprovechaba a partir de fuentes secundarias (Lortz, Lienhard, Congar, Iserloh, Moltmann). Al hacerse más asequible su obra gracias a las traducciones, los estudiosos de Lutero en América Latina han preferido acudir, por cuestiones de idioma, a las obras del reformador puestas en castellano. Sin duda un referente fundamental para la historiografía latinoamericana ha sido la obra Martín Lutero, publicada en 1976,

60. Tiene una edición brasileña reciente: Martinho Lutero, um destino. São Paulo: Três Estrelas, 2012. 61. De Manfred Kurt Bahmann, Carlos Witthaus, Heinz Joachim Held, Ernesto Weigandt, Joachim Fischer, Kenneth Mahler y Jacobo Preus.

62. Manfred Kurt Bahmann (1967: xi y xxxii). 
del jesuita español Ricardo García Villoslada, profesor de la Universidad Gregoriana de Roma, considerado el luterólogo más eminente de cultura y esencia hispánicas. Cabe mencionar también la edición que un año después hizo Marianne $\mathrm{O}$. de Bopp del manifiesto de Lutero, $A$ la Nobleza Cristiana de la nación alemana, publicado por la Universidad Nacional Autónoma de México. En 2001, el padre carmelita español Teófanes Egido sacó a la luz una selección de las obras de Lutero y un nuevo libro con motivo de la conmemoración de 2017, que ha tenido un claro impacto entre los estudiosos de este lado del Atlántico. ${ }^{63}$

Actualmente, no ha cesado el afán por traducir y publicar las obras de o sobre Lutero. Ejemplo de esto es el interés que hay en países como Brasil por traducir las obras que sobre el reformador y su teología hizo Helmar Junghans (1931-2010). Asimismo, en 2007, se tradujo al portugués la obra del teólogo alemán Hans Martin Barth, A teologia de Martim Lutero num contexto global (2007), misma que interesó a los teólogos latinoamericanos precisamente por situar la teología de Lutero en un amplio contexto del pensamiento humano, buscando elementos de esta tradición que fueran capaces de responder a los retos globales. Recientemente, en Argentina, la obra del teólogo alemán Hans Joachim Iwand (1899-1968) sobre una serie de estudios clásicos de la teología de Lutero ha sido traducida y editada por Daniel C. Beros teólogo e investigador del Instituto Superior Evangélico de Estudios Teológicos (ISEDET), acompañada de un estudio introductorio, refiriendo esa teología en el contexto de América Latina. ${ }^{64}$

\section{El siglo $\mathrm{xx}$ : viraje decisivo}

Los años sesenta del siglo xx fueron de gran trascendencia para la historiografía y la teología luteranas en América Latina. Entonces se consideró que las propuestas del reformador podían dar respuesta satisfactoria a las problemas sociales y confesionales del contexto latinoamericano. Por esta razón, los estudios sobre Lutero y, sobre todo, su doctrina, se abrieron al espectro de autores pertenecientes a comunidades eclesiásticas distintas y, la mayoría de los casos, ya no con características de mera confrontación.

El Concilio Vaticano II, orientado hacia el diálogo ecuménico, propició mayor interés por conocer a Lutero y se incrementaron los estudios sobre el reformador, sobre todo desde el punto de vista teológico. Al valorar la Reforma como un hecho histórico y como un periodo de crisis del cristianismo, esa importante reunión eclesiástica favoreció un diálogo comprensivo entre la teología católica y la luterana que se ha venido incrementando hasta nuestros días.

Por otro lado, la llamada Teología de la Liberación, que se gestó entre los años 1962 y 1968, también fijó su atención en Lutero y su doctrina, pues se con-

63. Teófanes Egido (2001) y (2017).

64. Hans J. Iwand en Beros (2015). 
sideró que en ello había elementos que podían esgrimirse para la lucha en contra de la pobreza y la desigualdad y en favor de la educación y de la liberación. Se buscaron enfoques interdisciplinarios (desde la economía, la sociología, la historia, la filosofía y la literatura principalmente) para abordar la personalidad de Lutero. El propio reformador fue analizado en sus aspectos vitales y, de nuevo, psicológicos; se tomó por algunos estudiosos como un campeón de la libertad de conciencia, héroe nacional de Alemania, paladín contra los autoritarismos, padre de la modernidad, el rebelde que se enfrenta a la opresión, el hombre que defendió el libre espíritu ante la fuerza ejercida por la iglesia, el patriota alemán que se alió con su pueblo contra el dominio de Roma.

De la Teología de la Liberación destacan las interpretaciones sobre Lutero del célebre teólogo franciscano brasileño Leonardo Boff (n. 1938), quien buscó «interrogar» al reformador a partir del horizonte de esta perspectiva. ${ }^{65}$ Sin embargo, como señalan Josep Ignasi Saranyana y Carmen Alejos Grau «en el diálogo con el catolicismo, son sin duda los luteranos los que han ido más lejos, teológicamente hablando... sobre todo a raíz de los puntos comunes con la teología católica de la liberación». ${ }^{66} \mathrm{El}$ debate protestante sobre este movimiento tuvo un amplio eco en Latinoamérica. Lee Brummel, de Argentina, analizó la hermenéutica de Lutero para entender a los pobres en los ańos setenta. Otro de los más prolíficos escritores sobre el reformador desde esta perspectiva ha sido Martín N. Dreher (n. 1945), ${ }^{67}$ pastor luterano y profesor de teología brasileño que hizo sus estudios en Alemania y quien, pese a no declararse teólogo de la liberación, entabló un diálogo muy interesante con los representantes de esta corriente, ofreciendo interpretaciones sobre la Teología de la Cruz en Lutero que, en su opinión, era un aspecto que cobraba cada vez mayor relevancia en América Latina. ${ }^{68} \mathrm{~A}$ partir de entonces y de manera ininterrumpida, han tenido lugar diversos espacios para el diálogo crítico, tanto en coloquios, conferencias y seminarios como en reuniones pastorales. Si bien en la actualidad, como señala Daniel Beros, «las corrientes progresistas deudoras del Concilio Vaticano II y la Conferencia Episcopal de Medellín (CELAM II), las experiencias de compromiso cristiano y popular de base y la "Teología de la Liberación», han sido mayormente relegadas a un papel institucional más bien marginal», ${ }^{69}$ no obstante, los estudios sobre Lutero han seguido adelante. Lo interesante del siglo xx y de lo que va del xxi es que, en la mayoría de los casos se ha abordado la figura del reformador desde América Latina con un espíritu crítico y un enfoque académico, poniendo en perspectiva tanto los aspectos positivos como negativos de su

65. Leonardo Boff (1984: 83).

66. Josep Ignasi Saranyana (dir.) y Carmen Alejos Grau (coord.) (2002: v. III, 468).

67. Se han citado algunas de las obras de Martin N. Dreher y de Brummel en la bibliografía.

68. Martin Dreher (1988 y 1990).

69. Daniel Beros, en H. J. Iwand (2015). Agradezco al autor la cortesía de haber compartido conmigo su manuscrito. 
persona, pero, sobre todo, generalmente lo han hecho con un profundo objetivo exegético de su obra, lo cual ha enriquecido considerablemente los estudios en torno a este tema.

Del lado del cristianismo evangélico, el teólogo luterano Hans-Jürgen Prien señalaba que la investigación bíblica protestante se encontraba totalmente subdesarrollada en América Latina cuando escribió en 1985 su obra La historia del cristianismo en América Latina. Según él, en Brasil, por ejemplo, teólogos católicos latinoamericanos, que habían hecho sus estudios en Europa o en los Estados Unidos, transmitían más la ciencia bíblica protestante que los propios seminarios protestantes locales. ${ }^{70}$ Ya en 1974, el teólogo evangélico ecuatoriano, René Padilla, había llevado a cabo uno de los intentos más tempranos de autocrítica a la teología luterana. ${ }^{71} \mathrm{Si}$ bien esto podía ser cierto en aquellas décadas, en los últimos años de lo que va del siglo Xxi las aportaciones sobre Lutero específicamente en América Latina inclinan la balanza de las contribuciones más hacia la historiografía protestante, producida en instituciones como La Fraternidad Teológica Latinoamericana, fundada en 1970, la Facultad de Teología de la Igreja Evangélica de Confissão Luterana no Brasil (IECLB), de São Leopoldo, fundada en 1946, la Facultad Luterana de José C. Paz en Argentina, cuya tradición hoy prosigue ISEDET, sede de la mayor biblioteca teológica protestante de América Latina, el Departamento Ecuménico de Investigación (DEI) de San José de Costa Rica, la Comunidad Teológica de México, el Instituto Pastoral Latinoamericano de Quito, Ecuador, y varios más. Sus investigadores han dialogado con luterólogos europeos como Dietrich Bonhoeffer, Jürgen Moltmann, Rudolph Bultmann, Paul Tillich y Marc Lienhard, entre otros. Además, la teología en América y Europa se ha visto favorecida con el intercambio de profesores invitados, que han impartido cátedra en universidades y centros teológicos en ambos lados del Atlántico. Sería casi imposible en este espacio mencionar las obras de todos ellos y menos aún la interpretación que le han dado a la figura del reformador. Basta decir que el crecimiento significativo que ha tenido el protestantismo en muchos países latinoamericanos ha generado un dinamismo en el interés particular en Lutero, en el origen de esta confesión y en sus principales fundamentos dogmáticos. Así, toda una gama de intelectuales señeros, de historiadores, teólogos, sociólogos, filósofos e incluso psicólogos han puesto su atención nuevamente en Lutero desde diferentes perspectivas. En cuanto a la investigación católica contemporánea sobre este personaje, el dominico Otto Hermann Pesch admitía en 1982 que el pensamiento del ex fraile agustino daba un aporte muy importante a la teología y a la historiografía católicas. Al respecto decía que se mostraba «un avance fructífero en el estudio de Lutero y la Reforma» que había contribuido a su mejor conocimiento, al mismo tiempo que había realizado un aporte importante al entendimiento entre ambas

70. H. J Prien (1985: 716).

71. René Padilla. Fe cristiana y Latinoamérica hoy. (Buenos Aires: Certeza, 1974). 
iglesias y, en general, al ecumenismo. ${ }^{72}$ Sin embargo, la investigación católica sobre Lutero en América Latina aún tiene mucho que ofrecer.

A lo largo de la segunda mitad del siglo xx, aparecieron artículos muy interesantes sobre diversos temas religiosos, muchos de los cuales comprendían análisis sobre Lutero y su teología, en diversas revistas, como el Boletín Teológico, de la Fraternidad Teológica Latinoamericana, publicada en México; Cuadernos de Teologia, de ISEDET en Argentina, la Revista Latinoamericana de Teología, de la Universidad Centroamericana "José Simeón Cañas» o Estudos Teológicos, de São Leopoldo, en Brasil, por mencionar sólo a algunas. Por otra parte, la Revista Ecclesiastica Xaveriana de Colombia dedicó un número especial a los 500 años del nacimiento de Lutero, y lo mismo hizo la Revista Latinoamericana de El Salvador, desde una perspectiva liberacionista. En 1983, para conmemorar esto mismo hubo discusión en jornadas interconfesionales, interdisciplinarias e internacionales sin precedentes, uno de cuyos objetivos fue analizar el significado de Lutero para un diálogo interreligioso e intercultural. ${ }^{73}$ Destacó un coloquio en la Semana Teológica Semestral organizado por el Instituto Superior de Estudios Teológicos (ISET) Juan XXIII y por el Servicio Ecuménico de Pastoral y Estudios de la Comunicación, sobre la vida y el pensamiento de Martín Lutero. Los trabajos presentados fueron publicados en un libro que lleva por título Lutero a la luz del siglo $X X .^{74}$ Desde un punto de vista católico, se analizó «el vigoroso aporte teológico del gran reformador Martín Lutero» para examinarlo a la luz de esa centuria.

Sin duda, uno de los teólogos latinoamericanos más destacados y que más ha contribuido en la actualidad al análisis sobre Lutero es el brasileño Walter Altmann (n. En 1944). Por la naturaleza de este trabajo, no es posible darle aquí el espacio que merece para ahondar en sus valiosas aportaciones. Su estudio Confrontación y liberación: una perspectiva latinoamericana de Lutero (1987) es el primer libro completo sobre Martín Lutero escrito por un teólogo latinoamericano, lo cual deja ver en seguida su importancia para el estudio y discusión de este tema. Además de haber profundizado en diversos aspectos de la teología de Lutero, «confrontándola con los desafíos que enfrenta la misión de la iglesia en América Latina», Altmann tradujo la obra del célebre pastor y teólogo alsaciano Marc Lienhard, responsable de la renovación de los estudios luteranos, cuyo título en portugués apareció como

72. Otto H. Pesch (2008: 384).

73. Helmar Junghans (2000: 121). Destaca la Declaración publicada por la comisión mixta católico-luterana el 6 de mayo de 1983 con el nombre Martín Lutero, testigo de Jesucristo, firmada por Hans Martensen, obispo católico de Copenhague y George Lindbeck, profesor de Yale, reunidos en Wittenberg, Alemania. Este documento partió de la revisión que los historiadores y teólogos católicos y luteranos habían realizado en el curso del siglo xx, lo que permitió un mejor acercamiento a la teología de Lutero por parte de los estudiosos católicos, y en América Latina no fue la excepción.

74. Juan Stumme, Luis Fernando Crespo, Gregorio Pérez de Guereńu (1983). 
Martim Lutero. Tempo, Vida, Mensagem, ${ }^{75}$ así como el de Hans Joachim Iwand, cuyo frontispicio en ese idioma quedó como A Justiça da Fé. Exposiçãa Conforme a Doutrina dé Lutero. ${ }^{76}$ Por su parte, Juan Stumme y Luis Fernando Crespo, publicaron ese mismo ańo el libro Lutero a la luz del siglo XX, que fue editado por el Servicio Ecuménico de Pastoral y Estudios de la Comunicación y el Instituto Superior de Estudios Teológicos Juan XXIII que recogía las ponencias presentadas en la Semana Teología Semestral donde se quería difundir «el vigoroso aporte teológico del gran reformador Martín Lutero». ${ }^{77}$

Con motivo de la conmemoración del nacimiento de Martín Lutero, se escribieron también obras de divulgación, como la de David J. Calvo El evangelista de la gracia de Dios, Martín Lutero, que incluía una selección de bellos grabados de la época y el estudio de Raúl Macín, Lutero: presencia religiosa y política en México. Además, diversos autores sacaron a la luz el libro Lutero: ayer y hoy (1984), ${ }^{78}$ un compendio de trabajos sobre el reformador, con una recopilación bibliográfica muy pertinente sobre obras escritas en español y portugués. Destacan también los artículos del pastor de la iglesia luterana de Bogotá, Roberto Hoeferkamp (1927-2012), "La viabilidad de Lutero hoy: una perspectiva desde América Latina» (1986) y de ese mismo año, "Como se estuda e vive Teología conforme Lutero" publicado en una obra cuya edición coordinó Lothar Hoch..$^{79} \mathrm{El}$ pastor Albérico Baeske, en Releitura de Lutero em contextos de Terceiro Mundo (1990), se acerca a la figura del reformador, como el propio autor explica, para aprovechar su teología para la militancia cristiana en estas regiones. ${ }^{80}$ Allí Lutero sería modelo para la materialización de la fe e inspiración para la vida en libertad que se ansia. Por su parte, Romeu Martini, en su Movimiento da Reforma e contexto Latino-Americano (1993) discute principalmente la postura de Lutero con su respuesta a los Doce Artículos ante los campesinos sublevados de Suabia, que culminó en la guerra de $1525 .{ }^{81}$ Es muy pronto para valorar las aportaciones realizadas desde América Latina en torno al tema de Lutero y la Reforma con motivo de las conmemoraciones por los 500 años de la publicación de las 95 tesis. En 2017 hubo interesantes reuniones académicas en los países hispanoamericanos y en Brasil y, a partir de esas reflexiones, seguramente pronto se tendrán numerosos análisis sobre diversos temas relacionados a este trascendente hecho histórico de tan larga duración, del tipo de los últimos estudios como el de Thomas Kaufmann, Lutero: vida, mundo y palabra (Granada, Trotta, 2017) y el de Lyndal Roper, Renegado y profeta (Barcelona, Taurus, 2017).

75. Las obras de Lienhard (n. 1935) suscitaron múltiples interpretaciones teológicas desde América Latina. Ver Luis F. Crespo en Stumme et al. (coord) (1983: 59).

76. Hans J. Iwand (1981).

77. Noé Zevallos en Stumme (1983: 3).

78. Remitimos al lector a la bibliografía general.

79. Remitimos al lector a la bibliografía general.

80. A. Baeske (1990).

81. Romeu R Martini y Eduardo Gross (1993). 


\section{Lutero en la conciencia literaria}

En el terreno de las bellas letras, Lutero tampoco ha pasado desatendido en el pensamiento latinoamericano. Lo vemos presente, incluso, en la poesía. ${ }^{82}$ Sobre todo desde el siglo XIX y, particularmente, en la segunda mitad del siglo xx, el personaje llamó la atención de autores de la talla de José Martí, Amado Nervo, Martín Luis Guzmán, Antonio Caso, Octavio Paz, Alfonso Reyes, Jorge Luis Borges, Carlos Fuentes, Alejo Carpentier o Julio Cortázar. ${ }^{83}$

A mediados del siglo xix, Domingo Faustino Sarmiento señalaba que «el cisma y la herejía» iniciadas por Lutero, junto con los posteriores cuestionamientos de Dumas y Víctor Hugo, habían dado origen al Romanticismo en el arte. ${ }^{84}$ Un siglo después, el premio nobel mexicano de literatura, Octavio Paz (1914-1998) también encontró paralelismo entre el protestantismo y el Romanticismo. ${ }^{85}$ Para él, al interiorizar la experiencia religiosa a expensas del ritualismo romano, el protestantismo preparó las condiciones psíquicas y morales del sacudimiento romántico, al convertir la conciencia individual del creyente en el teatro del misterio religioso, lo cual generó una cadena de consecuencias visibles e inmediatas en el plano sociopolítico. El Romanticismo fue, para Paz, una interiorización de la visión poética, la ruptura de la estética objetiva y más bien impersonal de la tradición latina y la aparición del yo poeta como realidad primordial. ${ }^{86}$

En 1915, volviendo atrás, Rubén Darío pronunció un discurso en la Universidad de Columbia en Nueva York un año antes de morir, en el que expresaba su idea de Dios, hablaba sobre la paz en los tiempos turbulentos de la Gran Guerra europea y sobre la influencia de Lutero en la música coral, para comentar después las circunstancias del conflicto bélico franco prusiano, tras el cual, en 1871, Alemania lograría su unificación nacional. ${ }^{87}$ Valga recordar que el poeta nicaragüense fue él mismo comparado con Lutero por José María Vargas Vila, por su faceta de «liberador», como «revolucionario de la Rima "que se alzó en rebelión contra los dogmas de la Métrica, y los rompió sobre la cabeza polvorienta de los dioses». ${ }^{88}$

82. El historiador Enrique de Olavarría y Ferrari (1844-1919) dice que tuvo acceso a una colección de loas y entremeses «que, a pesar de no hacer gloria a las letras patrias, son curiosos» y alguno incluía en sus décimas a Lutero. (1895: T. 1, 121-122). Por otro lado, para la presencia de Lutero en la poesía peruana reciente, ver Antonio Cisneros (2005: 52-53).

83. Ver Antonio Mendoza (2000: 31). Ariel Jordán Martínez (2011).

84. Cit. en Mariano Latorre (1971: 316).

85. Ver Miguel Domínguez Rohan (2013).

86. Leopoldo Cervantes Ortiz, «Sobre Octavio Paz», en Protestante Digital. 31 de marzo de 2014. También Octavio Paz (1982).

87. Rubén Darío (1949: 252). También en su colaboración en prosa «Los maestros: Núñez de Arce» se refiere a la interpretación de este pensador sobre el reformador. Guatemala Ilustrada, I, no. 2, 1892, p. 16.

88. José M. Vargas Vila (1917: 161, xxi). 
En la segunda década del siglo xx, apareció también Lutero en la poesía afroantillana y negrista del puertorriqueño Luis Palés Matos (1899-1959), "Canción festiva para ser llorada» y, lo interesante del caso, es que el personaje se asume dentro del contexto identitario caribeño. El reformador es referido como un ñánigo temerario, es decir un hombre que no conoce el miedo, pero no un $c a-$ rabali (individuo de raza negra africana de la costa de Calabar) sino un hombre de raza sajona, pero igualmente ejemplar por su carácter indómito, al desafiar al propio Papa. ${ }^{89}$ A continuación, un fragmento del poema...

\author{
Aquí está Santo Tomé \\ De malagueta y malanga \\ Cargando el burro que el cielo \\ De su Santidad demanda... \\ (su Santidad Babbitt Máximo, \\ con sello y marca de fábrica) \\ De su grave teología \\ Lutero hizo una fogata, \\ Y alrededor, Biblia en mano, \\ Los negros tórtolos bailan \\ Cantando salmos oscuros \\ A bombo, mongo de África
}

Por su parte, el escritor argentino Julio Cortázar refería en su «Distante espejo» (1943) que gustaba retirarse a Chivilcoy, lugar apartado de la bulliciosa Buenos Aires, donde se desempeñaba como profesor de la escuela Normal, para «estudiar a gusto: abro la Biblia de Lutero y estoy dos horas ingresando paso a paso en el alemán, regocijándome cuando soy capaz de leer un capítulo entero sin ayuda de mi Cipriano de Valera». ${ }^{90}$ En su Manual de instrucciones, vuelve a recordar al ex fraile alemán cuando hace la crítica de la pintura de Tiziano «El amor sagrado y el amor profano", e interpreta a su manera el mensaje del cuadro, al advertir con ironía que «el niño que mete la mano en el sarcófago es Lutero, o sea, el diablo» pero añade que «esta detestable pintura representa un velorio a orillas del Jordán... pocas veces la torpeza de un pintor pudo aludir con más abyección a las esperanzas del mundo en un Mesías que brilla por su ausencia.... ${ }^{91} \mathrm{Y}$ ya que hablamos de pintura, vale la pena contar la anécdota referida por Salvador Novo, que es difícil confirmar, y que refiere que el pintor mexicano Diego Rivera, pensaba en Lutero como un personaje idóneo para ser representado en los murales que le encomendaron pintar en Nueva York, proyecto que no llevó a cabo por la negativa de la familia Rockefeller. ${ }^{92}$ También al escritor argentino Jorge Luis Borges (1899-1986), le mereció

89. Jorge Luis Morales (1976: 89-90).

90. Julio Cortázar (1999: 1, 81).

91. Julio Cortázar (1962: 6; Antonio Mendoza (2000: 31).

92. Salvador Novo (2012). 
la pena mencionar al reformador. En su Deutsches Requiem publicado en 1949, un relato contenido en la colección El Aleph, ironizaba que Lutero había sido el traductor y al mismo tiempo destructor de la Biblia, al ponerla al alcance de cualquiera que pudiera interpretarla. ${ }^{93}$ Finalmente, en esta excerpta de escritores latinoamericanos que mencionan a Lutero, se incluyen las reflexiones de Carlos Fuentes, quien le llama a Lutero «el temible quirúrgico de la Iglesia de Roma», «el educador de la cristiandad», quien, paradójicamente, había sido considerado «el hereje, el réprobo, el autor prohibido" ${ }^{94} \mathrm{y}$ del escritor cubano Alejo Carpentier (19041980), quien además de ironizar que Lutero le había arrojado el tintero al diablo durante su dramático encierro en la Wartburg, destacaba la figura del reformador como compositor y como precursor del gran maestro Juan Sebastián Bach. En el prólogo de El reino de este mundo, recordó que, de sólida formación musical, a Lutero se le atribuían más de 70 corales, algunos compuestos por él y otros recogidos del pasado. ${ }^{95}$

\section{Lutero en la perspectiva del siglo XXI}

La tendencia para continuar analizando la figura y la teología de Lutero no ha cejado hasta nuestros días. En el Concilio Luterano internacional celebrado en Buenos Aires, Argentina, en el año 2000, el misionero estadounidense Douglas L. Rutt perfiló una interpretación interesante de Martín Lutero al comparar su experiencia vital con la de su contemporáneo, el sevillano Bartolomé de Las Casas, conocido como el protector de los indios, donde el autor encuentra varios paralelismos. Una década después, en Brasil, Helio Aparecido Teixeira llevó a cabo un análisis de los distintos periodos por los que había transitado el pensamiento de Lutero y se avocó particularmente a su concepción de "guerra justa». ${ }^{96}$ Por su parte, el educador de la Universidade Luterana do Brasil y Director de la Sociedad Bíblica de ese país, Leopoldo Heimann, coordinó una serie de volúmenes en los que se analizaban sus varias facetas como teólogo, educador, escritor, pastor y reformador. Heimann también publicó obras de Lutero traducidas al portugués. ${ }^{97}$ En Chile, el historiador Antonio Rehbein Pesce, quien fuera profesor de la Pontificia Universidad Católica de Santiago, volvió sobre la importancia de actualizar la figura de Lutero en la historiografía católica con el fin de ver también su significado para la Iglesia católica actual. Poco antes Marco A. Huesbe desde la Universidad Pontifica Católica de Valparaíso, había

93. Borges (1949).

94. Carlos Fuentes (2011: apartado 2).

95. Esto lo escribió para el periódico El Nacional, Caracas, 31 de agosto de 1952. En Alejo Carpentier (1987).

96. Sobre esto, ver Dougls Rutt (2000); Jean Pierre Bastián (1990) y (1997); Helio Aparecido Teixeira, (2011: 223-243).

97. Heimann, Leopoldo (2002-2006). 
presentado un trabajo sobre la propuesta política de Martín Lutero a través de su doctrina de los dos reinoss. ${ }^{98}$

En 1999, el novelista mexicano Francisco Prieto publicó una obra de teatro titulada «Lutero o el criado de Dios» y poco después, pero en Río de Janeiro, se estrenó el 26 de septiembre de 2002 otra obra dramática «Lutero: un hombre y dos destinos» dirigida por Paulo Faustino que expuso el pensamiento del reformador y su esencia como un hombre ético, íntegro y de fe profunda; un hombre brillante y un líder religioso. En 2006, el brasileño Arnaldo Érico Huff Júnior en un interesante estudio "Imagens de Lutero no luteranismo brasileiro» analizó las simbologías, imágenes visuales, textuales e imaginadas en la construcción de la idea del reformador hechas por pastores y líderes de la Iglesia Evangélica Luterana de Brasil (IELB) entre el final de la I Guerra Mundial a la posdictadura militar (1963-1985). Un fin similar persigue mi libro Lutero en el Paraiso (2008) donde se analiza la percepción de Lutero en México durante los tres siglos de régimen español. Por su parte, los filósofos mexicanos, Luis Guerrero y Ramón Kuri Camacho analizaron en sendos artículos, respectivamente en 1991 y 2013, la influencia de Lutero en Kierkegaard y en Heidegger. El historiador, teólogo y pastor Leopoldo Cervantes Ortiz y el escritor y periodista Carlos Martínez García, grandes promotores del Centro de Estudios del Protestantismo Mexicano organizaron la conmemoración del V Centenario de la Reforma en México. ${ }^{99}$

En septiembre de 2015, fue presentada en São Paulo, Brasil, una nueva edición en portugués del comentario de Lutero al Magnificat hecha por la Editorial Sinodal de la Iglesia Evangélica de Confesión Luterana en el Brasil [IECLB] y la editorial católica Santuario. Ese mismo año, el teólogo jesuita Héctor Vall Vilardel, desde Santiago de Chile, reflexionó sobre el papel de Lutero en la historia, apuntando ya a la próxima conmemoración luterana en una era ecuménica y global, que respondía a nuevas necesidades y nuevos retos teológicos, donde proliferaban nuevos movimientos religiosos, se revitalizaban religiones no cristianas, imperaban procesos de secularización y se exigía superar viejas rencillas confesionales que tendían a "sanar las memorias». Este autor ponderó la necesidad de «valorar positivamente el contenido teológico de algunas convicciones fundamentales de Lutero» así como «buscar el sentido profundo de su reforma ${ }^{100}$ Particularmente, importa resaltar la interpretación que hace este autor sobre el propio Lutero, como un "exégeta católico», un autor prolífico, un "profeta reformador», un hombre de carne y hueso que vivió un proceso

98. A. Rehbein (2001); Marco A. Huesbe Llanos (1999).

99. Francisco Prieto (1999); Arnaldo Érico Huff Júnior, (2006: 123-150 y 2003: 35-69); Mayer (2008); Ramón Kuri Camacho (2013); Luis Guerrero (1991: 983-992). Sobre el congreso organizado por Carlos Martínez y Leopoldo Cervantes, «Protestantismo y mundo moderno: A 500 años del inicio de la reforma luterana y su influencia en Iberoamérica», éste se llevó a cabo en la ciudad de México, los días 30 y 31 de octubre de 2017.

100. Val Vilardel (2015: 22-23). 
espiritual personal que impactó en su obra y en su pensamiento. El esfuerzo comprensivo por parte de este teólogo jesuita es un buen signo de cómo se ha de encarar la figura del reformador a lo largo de la conmemoración, a partir del año 2017, desde la perspectiva de la Iglesia católica.

Martin Hoffmann, teólogo alemán luterano, profesor invitado de teología sistemática de la universidad bíblica latinoamericana de San José de Costa Rica, presentó recientemente su libro La locura de la cruz. La teología de Martin Lutero. Textos originales e interpretaciones ${ }^{101}$ en que se analiza la actualidad de su pensamiento, sobre todo para el contexto de la diversidad religiosa de América Latina y el Caribe, donde las iglesias luteranas buscan profundizar su propia identidad espiritual y su compromiso social político a través de una imagen clara de su teología, a partir de la teología de la cruz como perspectiva central.

No se puede terminar este somero análisis de las principales obras que han tratado a Lutero en los últimos años sin destacar la importancia del proyecto que coordinó el profesor Ulrich Duchrow de la Universidad de Heidelberg quien, junto con otros colaboradores sacó a la luz cinco volúmenes, publicados en 2015, con estudios de reconocidos luterólogos de todo el mundo, que incluye más de una decena de investigadores latinoamericanos avocados a estudiar el mundo actual, en un contexto de crisis y retos, desde la perspectiva de la Reforma y de la investigación bíblica. ${ }^{102}$

\section{Temas actuales y líneas de investigación}

Hemos revisado hasta aquí los altibajos del proceso histórico de toma de conciencia de Martín Lutero en América Latina desde la producción historiográfica y teológica. Toca ahora apuntalar, también en apretada síntesis, algunas perspectivas para el estudio de los temas que tienen relevancia hoy en día en nuestro continente en cuanto a la interpretación de su persona y de su legado. Harto complicado resulta eso por los múltiples ángulos en los que puede ser abordado. Para los teólogos, Lutero se convierte en un tópico de referencia por el peso incuestionable de sus propuestas doctrinales y del sentido religioso cristiano de su existencia, mientras que, para los historiadores, lo es por la injerencia que tuvo su vida y su testimonio en el cambio de rumbo radical que siguió el mundo de entonces. Para los científicos sociales, Lutero es un revolucionario, que trascendió su original propuesta en el campo espiritual, para convertirse en uno de los principales causantes, sin proponérselo, de una revolución social, económica e ideológica. Se discute también sobre los factores psicológicos que su ética puso en juego. Los filósofos toman los rasgos esenciales de su conciencia cristiana para hablar sobre problemas de valores, de moral, del albedrío y de religión. Con

101. Martin Hoffmann (2014).

102. Ulrich Duchrow (2015). 
todo, el desafío de entender a Lutero desde nuestro contexto sigue teniendo una vigencia extraordinaria.

Algunas líneas de investigación pueden sugerirse, pero siempre se tendrá una deuda con las interpretaciones que ya se han hecho en el pasado. Difícilmente se encontrará un tema totalmente nuevo que no haya sido visto en esta larga pesquisa de siglos. Lo que sí es verdad es que siempre se puede analizar de manera original y novedosa al reformador a la luz de las propias circunstancias y de la actualidad y, en nuestro tiempo, se ha tratado de enraizar la teología y la espiritualidad de Lutero en la realidad específica de América Latina.

La investigación presente y futura se puede abrir hacia diferentes cauces en extensión y profundidad temáticas, pero siempre tendrá que tomar en cuenta algunos aspectos fundamentales. El primero sería la necesidad ineluctable de seguir trabajando en el estudio de Lutero como personaje histórico y de su significación para el mundo moderno. El segundo aspecto sería continuar la exégesis de su obra y ponderar la importancia que tiene ésta para cada generación que escribe su propia historia. El tercero es ver la propuesta de Lutero en el contexto de América Latina, en cuanto a la vigencia de su contenido y la pertinencia de su aplicación práctica.

Sobre el primer aspecto, decía Ortega y Medina que «hay que liberar al padre de la Reforma moderna, a Martín Lutero, de dos falsas interpretaciones, de dos máscaras o leyendas: la protestante, que lo ha considerado santo y la católica que lo ha visto y lo ha seguido viendo hasta hace poco como un demonio. ${ }^{103}$ Tan radical dicotomía ha impedido comprender a Lutero como persona y, más aún, como hombre de su propio tiempo, inmerso en el contexto del mundo germánico. Una vez hecho esto, el estudioso de Lutero debe buscar entender el verdadero espíritu religioso, su dramática búsqueda espiritual y personal con su Cristo íntimo que lo llevó al rechazo de la iglesia de su época.

Sobre la segunda propuesta, la del análisis permanente de su pensamiento a través del estudio de su obra, lleva a revisar de continuo temas fundamentales en Lutero, como la gracia, la justificación por la fe, la primacía de las Sagradas Escrituras sobre cualquier otra fuente, el papel de las obras, su concepto de libertad humana, el amor en la fe, la perspectiva soteriológica, el concepto de iglesia y de ministerio eclesial, la renovación de la liturgia, los problemas de ética y moral, a lo que se añaden puntos muy fundamentales como la Teología de la Cruz y la Eclesiología. Abordar a Lutero a partir de un profundo análisis de sus escritos es el mejor reconocimiento de su legado. El característico estilo retórico del reformador no esconde sus sólidos conocimientos en asuntos teológicos, morales y religiosos ni su más sincera labor espiritual. En su legado escrito, enorme por cierto, está lo que algunos llaman «el dogma luterano». ${ }^{104}$

103. Juan A. Ortega y Medina, en Cristina González y Alicia Mayer (2013: I, 443).

104. Juan A. Ortega y Medina, en Cristina González y Alicia Mayer (2013: I. 79-111). 
El tercer punto que hemos esgrimido se refiere a la actualidad de Lutero en la teología y en la historia de América Latina. Es inevitable que el estudioso de hoy no se fije en Lutero para tomarlo como referente ante la realidad actual. Por ejemplo, hoy existen varios estudiosos que han puesto su interés en los tópicos de la educación que planteó en su tiempo el reformador. ${ }^{105}$

El tópico del sacerdocio universal ha sido también discutido ampliamente, sobre todo para la praxis política y el actuar económico en el contexto del llamado subcontinente, mientras que el de la Teología de la Cruz $^{106}$ y la Eclesiología se han ligado a temas esenciales como el Ecumenismo o la Cristología orientados a comunidades eclesiales de base, la solidaridad con los pobres, con las víctimas de la violencia y la búsqueda de la liberación de los oprimidos, con la justicia como camino de salvación. Es verdad que la teología latinoamericana ha encontrado en Lutero una fuente de contenido social y humanitario.

Por otro lado, se impone la necesidad de que los especialistas sobre Lutero en América Latina sigan dándose a la tarea de debatir con estudiosos de todo el mundo. Actualmente se realizan numerosas negociaciones ecuménicas en el espíritu del mutuo reconocimiento de la comunidad de las iglesias inspirado por el reformador alemán. ${ }^{107}$ Enrique Dussel, presidente fundador de CEHILA (Comisión de Estudios de la Historia de la Iglesia en Latinoamérica) hacía énfasis en la definición ecuménica de iglesia como cuerpo de Cristo — siguiendo a Lutero- donde podría estar el punto de partida metódico para una historia del cristianismo. ${ }^{108}$ Por su parte, Hans Jürgen Prien aboga por una historiografía

105. Sobre todo en Brasil, esto ha tenido mucho eco en estudiosos como Luciana Muniz Ribeiro Barbosa (2011: 866-885; Antônio M. Araújo Gomes (2010); Albert Albori (2006- (2007); José Rubens Jardilino (2009); Leandro de Proença Lopes (2009); Ernesto Jacobo Kleim (2010); Cézar de Alencar Arnaut de Toledo (1999) y otros. También lo hicieron el estudioso alemán argentino Carlos Witthaus en sus varias colaboraciones, el venezolano Roldan Tomasz y otros (ver bibliografía general para las referencias completas).

106. Apoyado en el teólogo alemán Dietrich Bonhoeffer, para afirmar que la intención central de la reforma luterana era el Dios crucificado, Martin N. Dreher decía que en esto también descansaba la intención central de toda la auténtica teología latinoamericana. (1988: 137-138, 148. Ver también Guillermo Hansen (2004).

107. Como, por ejemplo, la declaración conjunta sobre la doctrina de la justificación, donde ha habido consenso a partir del Informe de Malta de 1972 y especialmente, tras la declaración conjunta sobre dicha doctrina en 1999, que significó un paso ecuménico de gran alcance. Para Walter Altmann, Lutero no fue indiferente a la vida ética de la justificación (1975: 25. Si bien el reformador negó la injerencia de las obras para la salvación, no por ello negó la autenticidad de las mismas como medios para hacer el bien al prójimo. Prien (1998: 90; André Birmele (1984: 341) y Val Vilardel (2015: 26). La consulta luterana sobre justificación y justicia se realizó en México en 1985, por invitación de la Misión Mundial de Cooperación Intereclesiástica de la Iglesia luterana norteamericana. Saranyana y Alejos (2008: 450). Por su parte, Boff explicaba que Lutero introdujo una radical liberación a la tesis básica de la justificación por la fe. Así lo expresa el teólogo brasileño: «La justificación por la fe es la expresión de una increíble libertad interior conquistada por Lutero y transformada en bandera de liberación». Boff (1983: 93).

108. Enrique Dussel, en Prien (1998: 14). 
ecuménica que debe nutrirse de un amplio conocimiento de eclesiología luterana, ya que Lutero no defendía solo una iglesia puramente espiritualizada, lo que tendría un enorme eco en América Latina. ${ }^{109}$ Como diría Albrecht Baeske la libertad de la gracia y de la fe sería la motivación para lograr en el llamado Tercer Mundo, la libertad política, económica, social y cultural cuyo fin último es llegar a una vida colectiva, digna y repartida, lo que Leonardo Boff llama «la dimensión liberadora de la fe». ${ }^{110}$

Por otra parte, ha habido también la necesidad de reconsiderar los aspectos de la ética en la obra de Lutero. Por la insistencia del movimiento reformador en la justificación por la sola fe, se acusaba al protestantismo de ser una religión sin ética, de oponerse a las buenas obras, a pesar de que Lutero salió varias veces al paso para explicar bien esta cuestión. Joachim Fischer en la "Presentación» a la obra de Lutero, "Comercio y usura» señalaba que el reformador se pronunció explícitamente acerca de ciertos problemas ético-sociales y tocó el tema del incipiente capitalismo. ${ }^{111}$ Esto ha generado una larga cauda de reflexiones en América Latina, donde se ha dejado claro que el reformador no fue indiferente a los problemas de la vida social y comercial de la Alemania de su tiempo.

Sin duda una de las discusiones más importantes en nuestro entorno latinoamericano es la que se refiere al tema de Lutero y su relación con la modernidad. Lutero está en el centro del debate, incluso, desde antes de que las ciencias sociales de inspiración weberiana relacionaron su reforma religiosa al surgimiento de una mentalidad nueva que inyectó fuerza a las energías económicas gestadas de tiempo atrás. El intelectual mexicano, Antonio Caso en 1915, afirmaba que «el rebelde fraile germánico, discípulo intrépido de san Pablo y San Agustín [había sido] el gran secularizador del cristianismo" y que la fuerza de su idea cristiana, íntimamente unida al espíritu del libre examen, le había dado su impronta a los tiempos modernos. ${ }^{12}$ Años después, Carlos Fuentes hacía notar que la severidad fatalista de Lutero desembocaría, paradójicamente, en sociedades de creciente libertad civil y desarrollo económico, en tanto que la fidelidad católica (erasmiana y jesuita expresamente) al libre arbitrio dentro de la ortodoxia cristiana contemplaría la parálisis económica y política impuesta al mundo español por el Concilio de Trento y la Contrarreforma. ${ }^{113}$ Octavio Paz habló en Conjunciones y disyunciones sobre las implicaciones del pensamiento de Lutero para el capitalismo moderno:

109. Prien (1998: 88).

110. Albérico Baeske (1990: 25); Boff (1983: 85).

111. Recientemente, el teólogo argentino Daniel Beros analizó la ética económica de Martín Lutero. Su objetivo era redescubrir su enfoque para un mejor entendimiento de la tesis weberiana. Para el autor, la ética económica de Lutero cuestiona la lectura y recepción de la tesis weberiana en el medio actual latinoamericano. Beros, Daniel C. (2007: 70-71). Ver también Ricardo Rieth (1996: 138).

112. Antonio Caso (1989: 15).

113. Fuentes (2011: s/p). 
La condenación del excremento por la Reforma, como encarnación o manifestación del demonio, fue el antecedente y la causa inmediata de la sublimación capitalista: el oro (el excremento) convertido en billetes de banco y acciones [...] Lutero recibe la revelación en la letrina, en el momento en que vacía el estómago. Las letrinas son el lugar infernal por definición. ${ }^{114}$

Leonardo Boff aludía a que se debía plantear la cuestión de hasta qué punto Lutero había propiciado una interpretación legitimadora de la modernidad, un sistema que, dicho sea de paso, para el teólogo brasileño había traído opresión sin cuento a grandes mayorías empobrecidas en la historia de América Latina. ${ }^{115}$ Tenía razón Boff cuando decía que este tema tan complejo era materia de estudio cuidadoso, ya que el fenómeno Lutero no podía quedar constreñido solamente a categorías religiosas, pues también había implicado una revolución social.

Si bien hoy América Latina cuestiona la modernidad en tanto que los países de origen germánico y sajón la ponderan, no siempre ha sido así. Desde el siglo XIX han existido voces a favor y en contra de sus valores y paradigmas. Enrique Dussel, es un ferviente defensor de la tesis de que el protestantismo no era causa, sino efecto de la modernidad. ${ }^{116}$ Para otros, el protestantismo en América Latina es la opción para incorporar a este continente a la dinámica progresista, siguiendo el modelo ejemplarizante de los Estados Unidos. La modernidad se convirtió en la meta anhelada para muchas naciones. La discusión sobre la "genética» protestante en la esencia de la modernidad cala particularmente hondo en América Latina, por su herencia ibérica y católica, que ha sido seńalada como causa de su actitud «misoneísta» o tradicional. Finalmente, como corolario a nuestros ejemplos, el teólogo alemán y profesor en la Universidad Bíblica latinoamericana de San José de Costa Rica, Martin Hoffmann, analiza cómo América Latina se enfrenta hoy a la crisis de la modernidad, un sistema que en su opinión está a punto de destruir sus propios fundamentos con una racionalidad que se ha vuelto instrumental. ${ }^{117}$

En suma, América Latina puede bien considerarse un importante escenario para los estudios de Lutero y del luteranismo fuera de Europa. Se trata de un contexto que mira la problemática desde otra y distinta óptica, en el estado actual del pensamiento y de la interpretación teológicas, tanto católicas como protestantes. Se piensa hoy, con razón, que Lutero puede ser maestro común para ambas.

El estado de la investigación histórica en la segunda mitad del siglo xx y lo que va del xxi es halagüeño. Han surgido nuevas interpretaciones y orientacio-

114. Paz (1969: 209-210).

115. Boff (1984: 91).

116. Enrique Dussel, en Prien (1998: 71-81).

117. Sin duda, en este terreno, el listado de obras sobre el tema es muy abundante. Para este trabajo, además de a Hoffmann, hay que revisar las tesis sobre la modernidad en Jean Pierre Bastian, de Juan A. Ortega y Medina, de Gonzalo Balderas Vega y de Roberto Blancarte citadas en la bibliografía, sólo como botones de muestra de la ingente producción sobre este aspecto. 
nes hermenéuticas y metodológicas de ciertos conceptos de Lutero que son de significación central para el diálogo ecuménico y misional. Por ello, no hay que soslayar lo producido en esta región, donde se ha ido construyendo una ingente historiografía y una importante reflexión teológica en los que el sujeto histórico y su testimonio pastoral han ganado terreno a una imagen falsificada o estereotipada del reformador y su labor y sus argumentos tomados como propuestas siempre sujetas a revisión e interpretación. 


\section{Abreviaciones}

AGN - Archivo General de la Nación, México

CONACULTA - Consejo Nacional para la Cultura y las Artes (México)

DEI - Departamento Ecuménico de Investigación de San José de Costa Rica

IECLB - Igreja Evangélica de Confissão Luterana no Brasil

IEPG - Instituto Ecuménico de de Pós-Graduação, Brasil

ISEDET - Instituto Superior Evangélico de Estudios Teológicos, Argentina

ISET - Instituto Superior de Estudios Teológicos Juan XXIII

FLACSO - Facultad Latinoamericana de Ciencias Sociales

UIA - Universidad Iberoamericana, México

UNAM - Universidad Nacional Autónoma de México 


\section{Bibliografía}

Alamán, Lucas, «Disertaciones sobre la historia de la república de México. Desde la época de la Conquista que los españoles hicieron a fines del siglo XVI y principios del Xvir... hasta la Independencia", en Obras de Lucas Alamán, Tomo III, México, Agüero Editores, 1849.

Alberdi, Juan A., Politica y sociedad en Argentina, Venezuela, Ayacucho, 2005. Albori, Albert. «Educaçáo, ética e cidadania na obra de Martim Lutero», Historia da Educação, 10 (20), (2006), 81-100.

—, "Relaçôes entre a etica social de Lutero e a concepção de Weber sobre a ética protestante no contexto educacional», Orbis: Revista de Ciencias Humanas, 7 (2007), 4-22.

Altamirano, Ignacio M., "El maestro de escuela», El Federalista, 20 de febrero de 1871.

Altmann, Walter, «Evangelização. Reflexão apartir de Lutero e no contexto ecuménico protestante mundial», Conferencia, 7-10 octubre de 1975, São Leopoldo, Facultad de Teología Cristo Rey, Pontificia Universidad Católica do Rio Grande do Sul.

—, "O Ministério Pastoral em Lutero. Algumas Teses e Breve Explicação", en Pastorado em Discussão, Huberto Kirchheim, editor, São Leopoldo, Editorial Sinodal, 1979, 26-34.

- (ed.), Confessando nossa Fé. Estudos da Confissão de Augsburgo para Uso das Comunidades. Elaborado por pastores de la Igreja Evangélica de Confissáo Luterana no Brasil, São Leopoldo, Editorial Sinodal, 1980.

—, "Lutero, afinal, o que quis?», en Reflexóes em torno de Lutero, vol. I, editado por Walter Altmann, compilado por Martin Dreher, Brasil, Edição Especial de Estudos Teológicos, 21 (1981), 9-28.

-, Confrontación y liberación: una perspectiva latinoamericana de Lutero, Buenos Aires, FOCO-ISEDET, 1983.

—, "Os 500 Anos do Nascimento de Lutero. Sob o signo da reaproximaçáo entre católicos e luteranos», Folha de São Paulo, Brasil (1983), 31.

—, Lutero e libertação, São Paulo, Ática, 1994.

Aranda Luna, Javier, «El Génesis de Carlos Monsiváis», La Jornada, México, 19 de octubre de 2011 (Sección Cultura).

Arcaute, David et. al., Lutero: ayer y hoy, Buenos Aires, La Aurora, 1984.

Auden, W.H., "Las tres crisis de Lutero», Critica, 57 (1994), 18-22.

Araújo Gomes, Antônio Maspoli, «Ética Cristã, Educação e Responsabilidade social em Martinho Lutero e João Calvino", Revista Ciências da Religião. História e Sociedade, 8 (2), (2010), 6-24.

BAEske, Albérico, «Releitura de Lutero em contextos de Terceiro Mundo», Estudos Teológicos, 30 (1990), 15-35.

Balderas Vega, Gonzalo, La Reforma y la Contrarreforma. Dos expresiones del ser cristiano en la modernidad, México, Universidad Iberoamericana, 1950. 
Bahmann, Manfred K., "Estudio preliminar», Obras de Martín Lutero, Buenos Aires, Paidós, 1967.

Barreda Laos, Felipe, Vida intelectual del virreinato del Perú, Lima, Universidad Nacional Mayor de San Marcos, 1964.

Bastian, Jean-Pierre, Historia del protestantismo en América Latina, México, CUPSA Editorial, 1990.

—, Protestantismos y modernidad latinoamericana. Historia de unas minorías religiosas activas en América Latina, México, Fondo de Cultura Económica, 1994.

-, La mutación religiosa en América Latina. Para una sociología del cambio social en la modernidad periférica, México, Fondo de Cultura Económica, 1997.

—, «La implantación y el desarrollo del efecto de doctrina y efecto de organización en el protestantismo misional en América Latina», en Hans-Jürgen Prien (ed.), Religiosidad e Historiografía. La irrupción del pluralismo religioso en América Latina y su elaboración metódica en la historiografía, FrankfurtMadrid, Vervuert Iberoamericana, 1998.

Bataillon, Marcel, Erasmo y España, México, Fondo de Cultura Económica, 1950.

Beros, Daniel C., «La ética protestante y el espíritu del capitalismo. Reflexiones a partir del pensamiento ético-económico de Martín Lutero», Cuadernos de Teología, vol. XXVI, Buenos Aires, Instituto Universitario ISEDET, (2007), 49-72.

—, «La importancia de la obra de Hans Joachim Iwand como intérprete de Lutero para el pensamiento teológico evangélico latinoamericano", prefacio, traducción y edición a Hans Joachim Iwand, Justicia de la fe. Estudios sobre la teología de Martín Lutero y de la Reforma Evangélica del siglo XVI, Buenos Aires, La Aurora, 2015.

Birmele, André, «Las cuestiones eclesiológicas en el diálogo internacional luterano-católico", en Cuestiones de Eclesiología y Teología de Martin Lutero. Actas del III Congreso Internacional de teología luterano-católica, Salamanca, 2630 de septiembre de 1983, editado por Adolfo González Montes, Salamanca, Centro de Estudios Orientales y Ecuménicos Juan XXIII, Universidad Pontificia de Salamanca, Centre D’Etudes Oecumeniques de Estrasburgo, Biblioteca Oecumenica Salmanticensis, 1984, 339-354.

BLANCARTE, Roberto, "Cristianismo y mundo moderno: una relación ambigua», en Cuadernos de Flacso, Toluca, Estado de México, El Colegio Mexiquense, núm. 3, mayo de 1993, p. 35-50.

Blank, Rudolfo, "Un vistazo al escudo de Lutero: acerca de la identidad luterana en el mundo hispano/latino", Missio Apostolica, 16 (1), (2008), 6-21.

Boff, Leonardo, «Lutero entre la reforma y la liberación», Revista Latinoamericana de Teología, 1 (1), (1984), 83-101.

Borges, Jorge Luis, El Aleph, Buenos Aires, Ed. Losada, 1949.

Brackel-Welda, Otto, Epistolas a Manuel Gutiérrez Nájera, prólogo y recopilación de Marianne O. de Bopp, México, UNAM, 1957. 
Brummel, Lee, Lutero ayer y hoy, Buenos Aires, La Aurora, 1984.

—, «El lenguaje bíblico de la pobreza en la hermenéutica de Lutero». Cadernos de Pesquisa, 41 (144), (2011), 866-885.

Bustamante, Carlos María de, Suplemento a la Historia de los tres siglos de México durante el gobierno español, escrita por el P. Andrés Cavo, preséntalo el Licenciado Carlos María de Bustamante como continuador de aquella obra, México, Imprenta de J. R. Navarro, 1852.

Calvo, David J., El evangelista de la gracia de Dios, Martín Lutero, Buenos Aires, Editorial Luz y Verdad, 1983.

Carpentier, Alejo, Obras completas, vol. X, México, Siglo XXI Editores, 1987.

Caso, Antonio, La existencia como economía, como desinterés y como caridad, México, UNAM, Facultad de Economía, 1989.

Castellanos, Juan de, Discurso del Capitán Draque. Antología Crítica. Elegías de varones ilustres de Indias, prólogo y edición de Luis Fernando Restrepo, Bogotá, Colombia, Pontificia Universidad Javeriana, 2004.

Castro Arcos, Javier, «David Trumbull, entre masonería y protestantismo: la conformación del frente anticlerial en Chile a fines del siglo XIX», Religião \&sociedade, 33 (1), (2013). $<$ http://dx.doi.org/10.1590/S0100-85872013000100006>

Cervantes Ortiz, Leopoldo, "Sobre Octavio Paz», Protestante Digital, 31 de marzo de 2014.

Cisneros, Antonio, "El reposo de un jesuita», en Leo Zelada (ed.), Nueva Poesía Hispanoamericana, 11, Madrid, Editorial Lord Byron, 2005.

CORTÁzAR, Julio, «Instrucciones para entender tres pinturas famosas», en Historia de Cronopios y de Famas, Buenos Aires, Alfaguara, 1962.

—, "Distante espejo», en Cuentos completos, Buenos Aires, Alfaguara, 1999.

Cortés, Hernán, «Carta a su procurador "ad litem” Francisco Núńez acerca de sus negocios ante la corte (con pasajes cifrados)», Cuernavaca, 25 de junio de 1532. Documentos cortesianos, José Luis Martínez (editor), México, Fondo de Cultura Económica, UNAM, 1991, t. III, 311-318.

DARío, Rubén, «Los maestros: Núñez de Arce», Guatemala Ilustrada, I (2), (1892), 16.

—, "Cuentos y crónicas», Antología poética, Arturo Torres Rioseco (ed.), Berkeley, Los Ángeles, University of California Press, 1949.

De Alencar Arnaut de Toledo, Cézar, «A questão da educação na obra de Martinho Lutero", Acta Scientiarum, 21 (1999), 129-135.

De Proença Lopes, Leandro, «Lutero \& a Edacação Brasil», Historia de la Educación Latinoamericana, 3 (2009), 295-298.

Dominguez Rohan, Miguel, «Hacia una teoría de la literatura de vanguardia en México", Revista de El Colegio de San Luis, 6 (2013).

Dreher, Luis H., «Da letra às ordens: teologia e ética do matrimônio em Lutero", Estudos Teológicos, 38 (3), (1998), 226-238.

Drener, Martin N., «A Redescoberta da Teologia da Cruz de Lutero no Debate com a Teologia da Libertação", Estudos Teológicos, 30 (1990), 15-35. 
—, "A theologia crucis de Lutero e o tema da teologia da libertação", Estudos Teológicos, 28 (2), (1988), 137-152.

—, "A Autoridade Secular A Visão de Lutero», Estudos Teológicos, 29 (1), (1989), 69-86.

—, Coleção História da Igreja, 4 vols., São Leopoldo, Sinodal, 2004.

—, «Martinho Lutero (1483-1546) e Tomas Müntzer (1489-1525), A justificação teológica da autoridade secular e da revolução política», Veritas, 51 (203), (2006), 145-168.

- (ed.), Reflexoes em torno de Lutero, 3 vols. Brasil, Faculdade de Teología da Igreja Evangélica de Confissao Luterana no Brasil, 1981.

Duchrow, Ulrich, (ed.), Daniel Beros, Martin Hoffmann, Hans Ulrich, Radicalizing Reformation, 5 Vols., Berlin, Münster, LIT Verlag, 2015.

Dussel, Enrique, Historia general de la Iglesia en América Latina, Salamanca, Ediciones Sígueme, 1983.

—, "Historia del fenómeno religioso en América Latina», en Hans J. Prien (ed.), Religiosidad e Historiografía. La irrupción del pluralismo religioso en América Latina y su elaboración metódica en la historiografía, Frankfurt-Madrid, Vervuert Iberoamericana, 1998, 71-81.

Egido, Teófanes, Martín Lutero. Una mirada desde la historia, un paseo por sus escritos, Salamanca, Ediciones Sígueme, 2017.

Echeverría, Esteban, "Discurso de introducción a una serie de lecturas en el Salón literario", en Obras escogidas, selección, prólogo y notas de Beatriz Sarlo y Carlos Altamirano, Biblioteca Ayacucho, 1991.

Fliedner, Federico, Martín Lutero, emancipador de la conciencia, prólogo de Darío A. Santamaría, Barcelona, Editorial Clíe, 1980.

FranzBaCh, Martin, «Las dos Alemanias en la obra de José Martí como lección histórica», en Horizont-Verschiebungen. Interkulturelles Verstehen und Heterogenität in der Romania. Festschrift für Karsten Garscha zum 60. Geburtstag, Claudius Armbruster y Karin Hopfe (eds.), Tübingen, Gunter Narr Verlag, 1998.

Fuentes, Carlos, "Julio Cortázar y la sonrisa de Erasmo», en La gran novela latinoamericana, México, Alfaguara, 2011, <www.libros/la-gran-novelalatinoamericana/MES063692> (cortesía de Alfaguara).

García Gutiérrez, Rosa, «Arias Montano en el Perú. La Academia de Lima y su discurso en Loor de la poesía», en Luis Gómez Canseco (ed.), Anatomía del humanismo, Benito Arias Montano (1598-1998). Homenaje al profesor Melquiades Andrés, Huelva, Diputación Oficial de Huelva-Universidad de Huelva, 1998, 319-338.

García Villoslada, Ricardo, Lutero visto por los historiadores católicos del siglo XX, Madrid, Fundación Universitaria Española, 1973.

Garcilaso De La Vega, Inca, La Florida del Inca, Barcelona, Red de Ediciones S.L., 2016.

Guerrero, Luis, «Fe luterana y fe católica en el pensamiento de Kierkegaard», Scripta Theologica, 23 (3), (1991), 983-992. 
Hansen, Guillermo, «El uso político de la cruz: poder y contra-poder en la Theología Crucis de Lutero", en Guillermo Hansen (ed.), El silbo ecuménico del espiritu: Homenaje a José Miguez Bonino en sus 80 años, Buenos Aires, Instituto Universitario ISEDET, 2004, 193-230.

Heimann, Leopoldo (ed.), Lutero o Teólogo, Brasil, Fórum ULBRA de Teología 5 Vols., Universidade Luterana do Brasil, 2004.

- (ed.), Lutero o Educador, Brasil, Fórum ULBRA de Teología, Universidade Luterana do Brasil, 2005.

Hoch, Lothar (ed.), Formaçâo teológica em terra brasileira, Sâo Leopoldo, Sinodal, 1986.

Hoeferkamp, Roberto T., «La viabilidad de Lutero hoy: una perspectiva desde América Latina», Vida y pensamiento, 6 (1), (1986), 5-13.

Hoffmann, Martin, La locura de la cruz. La teología de Martín Lutero. Textos originales e interpretaciones, Costa Rica, DEI, 2014.

Hojeda, Diego de, La Christiada, Sevilla, por Diego Pérez, 1611.

Huesbe Llanos, Marco A., «Reforma política luterana en el siglo xviI de Martin Lutero a Henning Arnisaeus», Revista de Estudios Histórico-Jurídicos, 21 (1999), 255-315.

Huff JúnIOR, Arnaldo Érico, «Imagens de Lutero no luteranismo brasileiro. Políticas e identidades na Igreja Evangélica Luterana do Brasil entre a I Guerra Mundial e o Pós-Ditadura Militar», Civitas. Revista de Ciências Sociais, 6 (2), (2006), 123-150.

—, «Pela fé e pelo amor: a construção de uma espiritualidade luterana original», $N u$ men: Revista de estudos e pesquisa de religião, Juiz de Fora, 6 (2), (2003), 35-69.

Iwand, Hans Joachim, A Justiça da Fé. Exposição Conforme a Doutrina dé Lutero. Traducido por Walter Altmann y Lindolfo Weingärtner, São Leopoldo, Sinodal, 1977 (2a ed. 1981).

Jardilino, José Rubens, Lutero \& a Educação, Brasil, Belo Horizonte, Autêntica Editora, 2009.

Jordán Martínez, Ariel, «Lutero en el pensamiento de José Martí», Tesis doctoral, Cuba, Seminario Concordia, 2011.

Junghans, Helmar, Temas da teologia de Lutero, São Leopoldo, Sinodal, 2000.

—, Da Teologia de Lutero, 2 ed. São Leopoldo, Sinodal, 2001.

KLEIM, Ernesto Jacobo, "A educação e a revolução social de Martinho Lutero", Eccos Revista Cientifica, 12 (1), (2010), 219-237.

Kuri Camacho, Ramón, «Existencia, destrucción y nominalismo de la gracia. Una mirada a Lutero, Kierkegaard, Peterson y Heidegger», Logos. Revista de Filosofia, 123 (2013), 5-44.

Latorre, Mariano, Memorias y otras confidencias, selección, notas y prólogo de Alejandro Calderón, Santiago de Chile, Editorial Andrés Bello, 1971.

Londoño, Juan Esteban, "Casafús era rojo: un malvado, un hereje». Identificación política-religiosa en Luterito de Tomás Carrasquilla», tesis doctoral, Colombia, Universidad de Antioquía, Instituto de Filosofía de Medellín, 2013. 
Lutero, Martín, Obras, Traducción de Carlos Witthaus y edición de Manfred Kurt Bahmann, 10 Vols., Buenos Aires, Paidós-El Escudo/La Aurora, 1967 ss.

—, Obras, Teófanes Egido (ed.), Salamanca, Ediciones Sígueme, 2001.

Macín, Raúl, Lutero. presencia religiosa y política en México, México, Ediciones Nuevomar, 1983.

Martensen, Hans, «Martín Lutero, testigo de Jesucristo», Ecclesia, 2136 (1983), 991-995.

Martini, Romeu R. y Eduardo Gross, Movimiento da Reforma e contexto Latinoamericano, IEPG, 1993.

MaYer, Alicia, Lutero en el paraiso. La Nueva España en el espejo del reformador alemán, México, Fondo de Cultura Económica, Universidad Nacional Autónoma de México, 2008.

—, «Luther in Latin America», en Derek Nelson y Paul Hinlicky (editores principales), The Oxford Encyclopedia of Martin Luther, vol. II, Johannes Zachuber (editor del volumen «Reception and Transformation»), Oxford, Oxford University Press, 2017.

Mendieta, Geronimo de, Historia Eclesiástica Indiana, México, Editorial Porrúa, 1971.

Mendoza, Antonio (ed.), Lecturas de museo. Orientación sobre la recepción de relaciones entre literatura y las artes, Santiago de Compostela, Barcelona, Universidad Santiago de Compostela-Universidad de Barcelona, 2000.

Meyer, Harding, "Lutero na Opinião da Igreja Católica Apostólica Romana», Estudos Teológicos, I (1961), 25-38.

Meza Fuentes, Roberto, De Díaz Mirón a Rubén Dario, 2 ed., Chile, Ediciones Andrés Bello, 1964.

Miegge, Mario, Martín Lutero (1487-1546). La Reforma protestante y el nacimiento de la sociedad moderna, traducción de Luiz Vázquez, prólogo de Alicia Mayer, Barcelona, Clíe, 2016.

MondraGón, Carlos, «Protestantismo, panamericanismo e identidad nacional», en Identidad y cultura nacional 1920-1950, Roberto Blancarte (coord.), México, Fondo de Cultura Económica, 1994, 305-342.

Mora, José María Luis, Obras sueltas, Tomo 2, París, Librería de Rosa, 1837.

Muniz Ribeiro Barbosa, Luciana, «Estado e educação em Martinho Lutero», Cadernos de Pesquisa, 41 (144), (2011), 866-885.

Nervo, Amado, Cuentos y Crónicas de Amado Nervo, prólogo de Manuel Durán, México, UNAM, 1993, Biblioteca del Estudiante Universitario, 95.

Novo, Salvador, «Siqueiros contra Rivera. Doce Rounds», Viajes y ensayos, II, México, Fondo de Cultura Económica, 2012.

Ocampo, Melchor, Obras completas, Tomo I, Polémicas religiosas, pról. de Félix Romero, notas de Ángel Pola, México, F. Vázquez Ed, 1900.

Olavarría y Ferrari, Enrique, Reseña Histórica del teatro Mexicano, Tomo I, México, La Europea, 1895. 
Ortega y Medina, Juan A., Reforma y Modernidad, Obras de Juan A. Ortega y Medina, Cristina González y Alicia Mayer (eds.), 7 volúmenes, México, UNAM-Instituto de Investigaciones Históricas, vol. I, 2013.

Padilla, René, Fe cristiana y Latinoamérica hoy, Buenos Aires, Certeza, 1974.

Palés Matos, Luis, "Canción festiva para ser llorada», en Poesía afroantillana y negrista, Jorge Luis Morales (ed.), Puerto Rico, República Dominicana, Cuba, Editorial de la Universidad de Puerto Rico, 1976.

Parra, Porfirio, Lutero. Cuadro dramático en un acto y en verso, México, Imprenta «El Correo Español», 1906.

Paz, Octavio, "Conjunciones y disyunciones», en Caravelle. Cahiers du monde hispanique et luso-brésilien, 2 (1969), 197-216.

—, "Independencia, modernidad, democracia», El Pais, 2 de mayo de 1982.

Pérez Martínez, Herón, «Misiva de Martín Lutero sobre el arte de traducir», en Relaciones. Estudios de Historia y sociedad, Zamora, México, El Colegio de Michoacán, XXXV, 138, 2014, 153-178.

Pesch, Otto Hermann, «Lo que en Lutero hay de católico», Gennium, 11 (2008), 384.

Prado Ferraz Costa, João Batista, "Vargas Llosa e Bento XVI», en O Estado de S. Paulo, Anápolis, Santamariadasvitorias, 24 de febrero de 2013.

Prien, Hans-Jürgen, La historia del cristianismo en América Latina, Salamanca, Editorial Sígueme, 1985.

—, "Consideraciones acerca de una eclesiología», en Religiosidad e Historiografía. La irrupción del pluralismo religioso en América Latina y su elaboración metódica en la historiografía, H.J. Prien, editor, Frankfurt-Madrid, Vervuert Iberoamericana, 1998.

Prieto, Francisco, Lutero o el criado de Dios, México, UNAM, 1999.

Ramírez, Ignacio, Obras, México, Oficina Tipográfica de la Secretaría de Fomento, 1889. Consultado en Microfilm 170-171, Universidad de Illinois.

Rehbein Pesce, Antonio, «Martín Lutero en la historiografía católica y en la iglesia católica actual», Teología y Vida, 42 (2001), 266-279.

Reyes, Alfonso, "Dos centenarios», en Retratos reales e imaginarios [1920], en Obras completas, vol. III, México, Fondo de Cultura Económica, 1980.

RIETH, Ricardo, "Habsucht» bei Martin Luther: ökonomisches und theologisches Denken. Tradition und soziale Wirklichkeit im Zeitalter der Reformation, Weimar, Böhlau, 1996.

Riva AgüERo, José, Obras completas, Tomo II, «Estudios de literatura peruana: Del Inca Garcilaso a Eguren», Lima, Pontificia Universidad Católica del Perú, 1962.

Riva Palacio, Vicente, Hernán Cortés. Ensayo histórico y filosófico en Ensayos Históricos, estudio preliminar de José Ortíz Monasterio, México, Conaculta, UNAM, Instituto Mexiquense de Cultura, Instituto de Investigaciones José María Luis Mora, 1997.

RoDó, José Enrique, «Liberalismo y jacobinismo» (1906), publicado en abril de 2011 en Juan O Pons, <http://constitucionweb.blogspot.com/>, noviembre de 2017. 
Rodríguez, Carmen y José D. Rodríguez (eds.), Martín Lutero descalzo: meditaciones sobre la identidad luterana desde el contexto latinoamericano, Santo Domingo, República Dominicana, 2010.

Roldán Tomasz SuÁrez, Litvin, «El sentido histórico del proyecto educativo de Lutero", Frónesis, 11 (1), (2004), 41-81.

Ruíz Guerra, Rubén, «El surgimiento del protestantismo en México: los pasos hacia una religiosidad republicana», en "De la Reforma a la Revolución 1857-1920», Javier Garciadiego, coordinador, en Gran Historia de México Ilustrada, IV, México, Planeta, 2001.

Rutr, Douglas L., «La misión de la Iglesia Luterana en América Latina. Análisis del pasado y perspectivas hacia el futuro", conferencia Lutheran International Council, Buenos Aires, Argentina, septiembre 26-28, 2000.

Saranyana, Josep Ignasi (dir.), Carmen Alejos Grau (coord.), Teología en América Latina, vol. III, Frankfurt-Madrid, Iberoamericana Vervuert, 2002.

-, Teología en América Latina, vol. II/2, Frankfurt-Madrid, Iberoamericana Vervuert, 2008.

Sarmiento, Domingo Faustino, Civilización y barbarie. Vida de Juan Facundo Quiroga y aspecto físico, costumbres y hábitos de la República Argentina, Buenos Aires, Puerto de Palos, 2006.

Sola, Sabino, El diablo y lo diabólico en las letras americanas, Bilbao, Universidad de Deusto, 1973.

Stoll, David, América Latina se vuelve protestante?, Quito, Abya Yala, 1993.

Stumme, Juan, Luis Fernando Crespo, Gregorio Pérez de Guereñu, Lutero a la luz del siglo XX, Lima, Sepec-ISET, Ed. Juan XXIII, 1983.

Teixeira, Helio Aparecido, «Aproximações entre Francisco de Vitoria e a sua crítica ao pacifismo de Lutero", Caurensia, Revista anual de Ciencias Eclesiásticas, VI (2011), 223-243.

VAl Vilardel, Héctor, «Del conflicto a la comunión: El sentido de las protestas de Lutero", Mensaje, LXIV (638), (2015), 21-28.

Valderrama Andrade, Carlos, "Jiménez de Quezada y el humanismo contrarreformista», Thesaurus, Biblioteca Virtual Cervantes, XX, núm. 2, 1965.

Vargas Vila, José María, Rubén Darío, Madrid, V.H de Sanz Calleja, 1917.

Varona, Enrique José, Ensayos, Barcelona, Ediciones S.L., 2016.

VIDAurre, Manuel Lorenzo, Proyecto de un código penal; contiene una explicación prolija de la entidad de los delitos en general y de la particular naturaleza de los más conocidos, Boston, Hiram Tupper, 1828.

Viejo Feliu, Ricardo, Lutero en España y América Española, Santander, Burgos, Nueva York, Fundadores Protestantes-Editorial Aldecoa, 1956.

Westhelle, Vitor, O Deus escandaloso. O uso e abuso da cruz, Sao Leopoldo, Sinodal, 2008 [en inglés, Minneapolis, Fortress, 2006].

—, "Luther in Lateinamerika und Boff in Deutschland: lutherische Theologie in Lateinamerika und ihre Anfragen an Europa», en Luthers Unvollendete: Relevanz lutherischer Theologie aus europäischer und lateinamerikanischer 
Perspektive, Claudia Jahnel and Hans Zeller, eds., Erlangen, Martin-Luther Verlag, 2013, 13-28.

—, «Exploring Effective Context: Luther's Contextual Hermeneutics», en You have the Words of Eternal Life: Transformative Readings of the Gospel of John from a Lutheran Perspective, Documentation 57/2012, Kenneth Mtata, ed., Minneapolis, MN, Lutheran University Press, 2012, 107-120.

—, "Theology of the Cross: A theology of revelation and a Lutheran understanding», The Lutheran, 25 (10), (2012), 18-19.

—, "Lutheranism and Culture in the Americas: A Comparative Study», en Transformations in Luther's Theology: Historical and Contemporary Reflections, Christine Helmer \& Bo Kristian Holm, editores, Arbeiten zur Kirchen- und Theologiegeschichte 32, Leipzig, Evangelische Verlagsanstalt, 2011, 229-244.

—, "Hybridity and Luther's Reading of Chalcedon», en Gudstankenaktualitet: Bitrag om teologiens opgave og protestantismens indre spaendinger: Festskrift til Peter Widmann, Else Marie Wiberg Pedersen, Bo Kristian Holm, AndersChristian Jacobsen, editores, Copenhagen, ANIS, 2010, 233-253.

—, "Power and Politics: Incursions in Luther's Theology», en The Global Luther: A Theologian for Modern Times, Christine Helmer, editor, Minneapolis, Fortress Press, 2009, 284-300.

-, "Uses and Abuses of the Cross: The Reformation, Then and Now», Trinity Seminary Review, 28 (2), (2007), 83-91.

—, "Luther on the Authority of Scriptures», Lutheran Quarterly, 19/4 (2005), 373-391.

—, "The Word and the Mask: Revisiting the Two-Kingdoms Doctrine», en The Gift of Grace: The Future of Lutheran Theology, Niels Henrik Gregersen, Bo Holm, Ted Peters, and Peter Widman, editores, Minneapolis, Fortress, 2005, 167-178.

—, "The Dark Room, the Labyrinth and the Mirror: On Interpreting Luther's Thought on Justification and Justice», en By Faith Alone: Essays on Justification in Honor of Gerhard O. Forde, Joseph A. Burguess and Marc Kolden, editores, Grand Rapids: Eerdmans, 2004, 316-331.

-, "Communication and the Transgression of Language in Luther», Lutheran Quarterly, 17/1 (2003), 1-27.

-, "Cross, Creation, and Ecology: The Meeting Point Between the Theology of the Cross and Creation Theology in Luther", en Concern for Creation: Voices on the Theology of Creation, Viggo Mortensen, editor, Uppsala, Tro \& Tanke, 1995, 159-167.

Withauss, Carlos, "Martin Lutero como pedagogo", Cuadernos de Teología, (1972), 139-146. 
